\title{
EL BREXIT Y SU IMPACTO EN LA EUROPA DE LOS DERECHOS: \\ EL DESAFÍO BRITÁNICO AL DERECHO CONSTITUCIONAL EUROPEO
}

BEATRIZ TOMÁS MALLÉN 
SUMARIO

I. INTRODUCCIÓN: EL BREXIT COMO CONSECUENCIA DEL EUROESCÉPTICO CONSTITUCIONALISMO BRITÁNICO. II. EL REINO UNIDO COMO PROMOTOR (PARADÓJICAMENTE) DE LA EUROPA AMPLIA DE LOS DERECHOS. 1. La emblemática constitución en Londres del Consejo de Europa. 2. La tardía asunción de los estándares básicos de la cultura europea de los derechos. III. LA INICIAL EXCLUSIÓN Y LAS SUCESIVAS EXCEPCIONES BRITÁNICAS A LA EUROPA COMUNITARIA DE LOS DERECHOS. 1. La EFTA y la promoción de la Europa integrada de los derechos, sin integrarse en ella. 2. Las excepciones parciales sobre derechos en las reformas de los Tratados europeos. 3. La enmienda a la totalidad a la Europa de los derechos: el rechazo a la Carta de los Derechos Fundamentales de la Unión Europea. IV. LA HOJA DE RUTA DEL BREXIT COMO ABANDONO DEL ORDEN CONSTITUCIONAL EUROPEO DE LOS DERECHOS. 1. El distanciamiento respecto al catálogo europeo de derechos. 2. La desconsideración hacia el TJUE. 3. La hoja de ruta en la encrucijada: la tenue frontera entre la Unión Europea y el Consejo de Europa. V. REFLEXIONES FINALES: LA APUESTA POR EL FORTALECIMIENTO DE LA EUROPA DE LOS DERECHOS, PESE AL BREXIT. 


\title{
EL BREXIT Y SU IMPACTO EN LA EUROPA DE LOS DERECHOS: EL DESAFÍO BRITÁNICO AL DERECHO CONSTITUCIONAL EUROPEO
}

\author{
BEATRIZ TOMÁS MALLÉN \\ Profesora Titular de Derecho Constitucional \\ Universitat Jaume I
}

\section{INTRODUCCIÓN: EL BREXIT COMO CONSECUENCIA DEL EUROESCÉPTICO CONSTITUCIONALISMO BRITÁNICO}

A la vista del proceso de salida del Reino Unido de la Unión Europea conocido como Brexit conviene analizar su impacto desde la perspectiva de la Europa de los derechos o, si se prefiere, del elemento nuclear o sustancial (dogmático, diríamos) del proceso de constitucionalización de Europa. En efecto, el Brexit, que se inició con su utilización electoralista por el Premier británico Cameron ${ }^{1}$,

\footnotetext{
${ }^{1}$ Como señala Castellà Andreu, J. M., «el referéndum ha encontrado su lugar en el sistema constitucional, sobre todo en los últimos años como instrumento en manos del primer ministro y la mayoría, lo que propicia su convocatoria con base a factores políticos que dependen de su conveniencia política, sobre todo durante los gobiernos Cameron, desde 2010. Se traslada al cuerpo electoral una decisión fundamental en lugar de ser tomada por las instituciones representativas. El recurso al referéndum expresa más una ausencia de liderazgo capaz de unificar al propio partido y convencer a la opinión pública sobre una decisión, que se considera conveniente para el bien común, que una forma de entender la democracia, en la que la participación popular directa ocupa un lugar relevante en la toma de decisiones públicas», «El referéndum sobre el Brexit: una historia inacabada», Revista de Derecho Político, n. ${ }^{\circ}$ 97, 2016, p. 302.
} 
siguió con el ajustado e inesperado resultado del referéndum de 23 de junio de 2016 favorable a la salida de la Unión Europea y continúa su recorrido, ha dado una lamentable vuelta de tuerca a ese proceso europeo de integración y constitucionalización.

La posterior sentencia del Tribunal Supremo del Reino Unido de 24 de enero de 2017 que declaró necesario el trámite formal de autorización parlamen$\operatorname{taria}^{2}$ no fue sino un mero obstáculo procedimental de orden constitucional interno que solo retrasó unos meses la comunicación oficial del Gobierno británico a la Unión Europea (UE) sobre su decisión de retirada, siendo realmente la voluntad política de dilatar el plazo al máximo lo que determinó la demora. Es verdad que, con toda seguridad, esa sentencia vino inducida por lo apretado del resultado - un $51.9 \%$ favorable a la salida frente a un $48.1 \%{ }^{3}$, y que ello nos podría llevar a reflexionar sobre la legitimidad de esa frágil mayoría que decidió romper formalmente con la condición de socio comunitario mantenida durante más de cuatro décadas - y sobre la influencia en esa legitimidad del nivel de información que la ciudadanía tenía sobre las implicaciones de tamaña decisión— ${ }^{4}$, pero lo cierto es que el Reino Unido ha ejercido un acto de soberanía confirmatorio de un constitucionalismo que podríamos calificar como euroescéptico.

${ }^{2}$ Véase la versión original de dicha Sentencia en la web oficial de la Supreme Court of the United Kingdom, https://www.supremecourt.uk/news/article-50-brexit-appeal.html (consultado el 20 de abril de 2017). En el apartado 2 se sintetizan los términos de la controversia: «In December 2015, the UK Parliament passed the European Union Referendum Act, and the ensuing referendum on 23 June 2016 produced a majority in favour of leaving the European Union. UK government ministers (whom we will call «ministers» or «the UK government») thereafter announced that they would bring UK membership of the European Union to an end. The question before this Court concerns the steps which are required as a matter of UK domestic law before the process of leaving the European Union can be initiated. The particular issue is whether a formal notice of withdrawal can lawfully be given by ministers without prior legislation passed in both Houses of Parliament and assented to by HM The Queen». El fallo de la Corte Suprema fue: «The Supreme Court considers that the terms of the ECA (the European Communities Act 1972), which gave effect to the UK's membership of the EU, are inconsistent with the exercise by ministers of any power to withdraw from the EU Treaties without authorisation by a prior Act of Parliament».

${ }^{3}$ Desde una posición contraria, Lawyers for Britain han criticado que se haya pretendido desvirtuar el resultado del mediante recursos jurisdiccionales, «The referendum result is binding», http://www.lawyersforbritain.org/referendum-binding.shtml (acceso el 20 de julio de 2017).

${ }^{4}$ BoyLe, K., «The legitimacy of the EU referendum requires that citizens are informed of the implications of their decision», Democratic Audit UK, 22 de abril de 2016, http://www. democraticaudit.com/2016/04/22/the-legitimacy-of-the-eu-referendum-requires-that-citizensare-informed-of-the-implications-of-their-decision/ (visitado el 19 de julio de 2017). 
Podrá criticarse, y con razón, la postura insolidaria de quienes han votado a favor del Brexit por lo que supone de ataque al proceso europeo de constitucionalización. Sin embargo, quienes deseaban la permanencia en la UE no siempre han hecho gala de «sentimiento constitucional» europeo ${ }^{5}$, ni han aparecido como una «ciudadanía europea activa» ${ }^{6}$, pecando en ocasiones por omisión, especialmente quienes no acudieron a las urnas quizá pensando que Europa se construye sola.

Los defensores de la UE — sobre todo dentro del Reino Unido pero no solo_- deberían haberse movilizado más. Y tenían también una buena base histórica para hacerlo pues, como es sabido, el Reino Unido fue promotor de la Europa amplia de los derechos con una actitud solidariamente acogedora de europeos continentales durante la Segunda Guerra Mundial e impulsor del Consejo de Europa, la organización paneuropea de cooperación por excelencia tendente, precisamente, a hacer imperar la salvaguardia de los derechos.

No obstante, esa dinámica británica favorable a la cooperación europea no fue acompañada, desde el inicio, por una paralela dinámica de integración europea, como lo acredita que la idea de los «Estados Unidos de Europa» lanzada por Churchill en el famoso discurso pronunciado en la Universidad de Zurich el 19 de septiembre de 1946 no se concretara en la condición del Reino Unido como país fundador de las Comunidades Europeas en 1951 a través del Tratado de la $\mathrm{CECA}^{7}$. Al contrario, el Reino Unido se mantuvo al margen de la constitución formal del proyecto comunitario europeo, sumándose posteriormente con una

\footnotetext{
5 Sobre esta idea, puede verse TAJAdura TEJADA, J., «El sentimiento constitucional», Claves de la Razón Práctica, n. ${ }^{\circ} 77,1997$, pp. 72-74 y más ampliamente, LuCAs VERdú, P., El sentimiento constitucional. Aproximación al estudio del sentir constitucional como modo de integración política, Madrid, Reus, 1985.

${ }^{6}$ Lo que no resulta tarea fácil. Como señala, PÉrez de las Heras, B., «sin prescindir de los necesarios esfuerzos que deben desplegarse desde la propia Unión, las escuelas y los centros de educación deben asumir la primera y más primordial misión de promover una ciudadanía europea activa entre los niños y los jóvenes, formándolos sobre los orígenes y la significación política del proceso de construcción europea, los valores y principios fundamentales sobre los que se asienta, así como sobre sus instituciones y sus principales realizaciones», «La Constitución para Europa y la promoción de la ciudadanía europea», Europa Euskadi, n. ${ }^{\circ}$ 166, 2004, p. 6.

7 Becerril Atienza, B. (Ed.), Europa unida. Dieciocho discursos y una carta. Winston S. Churchill, Ediciones Encuentro, Madrid, 2016. En dicha obra se reúnen dieciocho discursos (y una carta) pronunciados por Churchill desde el fin de la segunda guerra mundial hasta su muerte en relación con el proyecto europeo de integración. Aunque Churchill no llegara a ser testigo de la incorporación del Reino Unido a las Comunidades Europeas ni podamos saber prospectivamente qué hubiera pensado acerca de la consumación del Brexit, la editora y prologuista concluye que la consciente ambigüedad de los discursos churchillianos (no propugnando resueltamente la adhesión del Reino Unido a la Europa comunitaria, pero tampoco postulando una cerrazón absoluta a con-
} 
posición siempre pretendidamente excepcional ${ }^{8}$. Y ese juego de las excepciones es el que, desafortunadamente, se ha convertido en la regla general que ha guiado a los promotores del Brexit y la hoja de ruta de las negaciones entre el Reino Unido y los Estados comunitarios en el marco del artículo 50 del Tratado de la Unión Europea (TUE).

En tal escenario, esas negociaciones se están produciendo en buena medida, como no puede ser de otro modo, en torno al estatuto jurídico con el que quedarán tanto la ciudadanía británica en el seno de la UE de los Veintisiete como, correlativamente, la ciudadanía europea en el Reino Unido; todo un reto constitucional para la Europa de los derechos. A tal efecto, resaltando el papel a jugar en este terreno por el TJUE", se ha advertido que si la Premier británica «se aferra a sus armas para resistir cualquier papel post-Brexit para la protección judicial internacional o europea eficaz de los derechos de los ciudadanos de la UE en el Reino Unido (una obsesión sin duda exacerbada por su tiempo en el Home Office), ello puede ser suficiente para hundir las negociaciones antes de que realmente comiencen» ${ }^{10}$. Todo ello, por descontado, sin perder de vista la paralela cuestión esencial de la vinculación económica a mantener el Reino Unido con la UE, especialmente en un panorama «post-Brexit» en el que algunos indicadores alertan sobre el debilitamiento de la economía británica ${ }^{11}$.

Compartiendo que, como se señala en la Declaración Schuman de 9 de mayo de 1950 , Europa se va construyendo a través de «realizaciones concretas, que creen primero una solidaridad de hecho», no puede sino constatarse que el Reino Unido ha dado un paso atrás cargado de insolidaridad. Pero ya no es tiempo

vertirse en Estado miembro) no le restan valor a su condición de gran valedor, entusiasta y «mecenas» de la unidad europea.

${ }^{8}$ El propio Churchill, como recuerda Riestra, L., había declarado: «"Estamos con Europa, pero no en ella. Estamos vinculados, pero no comprometidos". La frase pertenece a un artículo publicado en 1930 en el Saturday Evening Post por Winston Chruchill. Quién le iba a decir que, años después, sería cientos de veces citada por los políticos británicos en un contexto tan complejo como es el del "brexit"», «Una historia de amor-odio con Churchill como nexo», http://projects. huffingtonpost.es/brexit/ (acceso el 6 de junio de 2017).

9 Vid. Silveira, A., «On the CJEU's post-Brexit case-law on European citenship. The recovery of the identity Ariadne's thread?», UNIO-EU Law Journal, vol. 3, n. ${ }^{\circ} 1,2017$, pp. 48-62.

${ }^{10}$ McCrudden, C., «An Early Deal-Breaker? EU Citizens' Rights in the UK after Brexit, and the future role of the European Court of Justice», 27 de junio de 2017 (https://ukconstitutionallaw.org/2017/06/27/christopher-mccrudden-an-early-deal-breaker-eu-citizens-rights-inthe-uk-after-brexit-and-the-future-role-of-the-european-court-of-justice/, acceso el 21 de septiembre de 2017).

${ }^{11}$ GiLes, C., «The UK economy since the Brexit vot-in 5 charts», Financial Times, 26 de julio de 2017 (https://www.ft.com/content/cf51e840-7147-11e7-93ff-99f383b09ff9, visitado el 19 de septiembre de 2017). 
de lamentaciones ${ }^{12}$ sino de procurar que ese paso nos aleje lo menos posible de la meta e incluso - ¿por qué no intentarlo? — pueda servir para coger impulso. Como ha observado el Parlamento Europeo, más allá de las consecuencias económicas, el peligro real del Brexit es ideológico y político, de tal manera que la única posible respuesta radica en impulsar la integración europea y la democra$\mathrm{cia}^{13}$. Sobre estas cuestiones pretendemos reflexionar en este trabajo.

\section{EL REINO UNIDO COMO PROMOTOR (PARADÓJICAMENTE) DE LA EUROPA AMPLIA DE LOS DERECHOS}

\section{La emblemática constitución en Londres del Consejo de Europa}

Aunque Churchill no concretara las bases evolutivas de lo que hoy es la UE en su ya mencionado discurso de Zurich — eso lo haría más tarde la Declaración Schuman de 9 de mayo de 1950, manifestándose entonces la exclusión originaria del Reino Unido del proyecto integrador de vocación federal—, es justo reconocer que las vislumbró al proponer que «debemos crear la familia europea con una estructura regional llamada, quizá, los Estados Unidos de Europa» y que el «primer paso es crear un Consejo de Europa». No es casual, por tanto, que la firma del Estatuto del Consejo de Europa tuviera lugar, el 5 de mayo de 1949, en el St Jame's Palace de Londres, siendo los diez países inicialmente signatarios Bélgica, Dinamarca, Francia, Irlanda, Italia, Luxemburgo, Holanda, Noruega, Suecia y el Reino Unido ${ }^{14}$.

Volviendo al discurso de Churchill, debe constatarse que alberga, aun sin poner el acento explícitamente en los derechos humanos, la idea de la Europa

${ }^{12} \mathrm{Y}$, al contrario, siempre es tiempo de esperanza. En este sentido pueden interpretarse las palabras de Moreno Fernández, L.: «De la misma manera que por factores contingentes y circunstanciales se produjo dicha pequeña mayoría, la situación podría cambiar en un futuro indeterminado. Ello sólo sería posible si una mayoría de los propios británicos volviesen a creer en Europa. Para ello se requiere convicción y entereza en los negociadores continentales», «Theresa May, la ganadora todo se lleva», Catalunya Press, 21 de abril de 2017, http://www.catalunyapress. es/texto-diario/mostrar/722000/theresa-may-ganadora-todo-lleva (acceso el 8 de junio de 2017).

13 Así lo señala la Eurocámara en su estudio Brexit and the European Union: General Institutional and Legal Considerations, Committee on Constitutional Affairs, PE 571.404, January 2017, p. 49.

14 Por ello, cada 5 de mayo se celebra la «Jornada de Europa» desde que el Comité de Ministros del Consejo de Europa la instituyera en 1964. Con posterioridad, en 1985, y a su semejanza, se instituyó el «Día de Europa», que festeja la existencia de la UE cada 9 de mayo (por la Declaración Schuman), tras acordarlo así, reunidos en Consejo Europeo, los Jefes de Estado y de Gobierno de los entonces diez socios comunitarios: Alemania, Bélgica, Dinamarca, Francia, Grecia, Irlanda, Italia, Luxemburgo, Holanda y el Reino Unido. 
amplia de los derechos (la del Consejo de Europa de los actuales 47 Estados miembros), al apelar a los «principios y concepciones» de la Sociedad de Naciones y al reforzamiento en el plano regional de la Organización de las Naciones Unidas, sosteniendo que «la salvación de la gente normal de cada raza y de cada país, del peligro de la guerra o la esclavitud, debe establecerse sobre sólidos fundamentos, los cuales han de estar protegidos por la voluntad de todos los hombres y mujeres de morir, antes de someterse a la tiranía». Ello va en la línea, verdaderamente, del destacado papel que jugó el Reino Unido junto a las tropas aliadas para liberar al continente europeo del yugo totalitario del nazismo.

Consiguientemente, tampoco debe sorprender que el Estatuto del Consejo de Europa, tras reafirmar en el Preámbulo la adhesión de los Estados fundadores «a los valores espirituales y morales que son patrimonio común de sus pueblos y la verdadera fuente de la libertad individual, la libertad política y el imperio del Derecho, principios sobre los cuales se funda toda auténtica democracia», señale en el artículo 1.b) como finalidad de la Organización «la salvaguardia y la mayor efectividad de los derechos humanos y las libertades fundamentales».

Con apoyo en dichas bases habilitantes, y el previo espaldarazo del Congreso de la Haya de 10 de mayo de 1948 (en cuyo marco el Reino Unido ya mostró sus dudas sobre el alcance de los instrumentos unificadores) ${ }^{15}$, se adoptó en un tiempo récord, concretamente el 4 de noviembre de 1950 en Roma, el Convenio Europeo de Derechos Humanos, que se reveló como un eficaz antídoto frente al totalitarismo ${ }^{16}$. Entró en vigor el 3 de septiembre de 1953 tras reunir las diez ratificaciones requeridas ${ }^{17}$.

En todo caso, la formal catalogación del Consejo de Europa como organización de cooperación (teóricamente más respetuosa con la soberanía estatal) y su comparación con la organización de integración (la actual UE), no ha estado exenta de matizaciones en la evolución del Derecho constitucional europeo. Pues, en realidad, difícilmente cabe desconocer el creciente impacto constitucional de las resoluciones del TEDH (y, por supuesto, del TJUE) ${ }^{18}$. Como tampoco cabe

15 Véase «Origin and development of the Council of Europe. The idea of convening a European assembly», en Centre Virtuel de la Connaissance sur l'Europe (CVCE), http://www.cvce.eu/ obj/origin_and_development_of_the_council_of_europeen-588dec89-3400-4e32-88694484e6b64f51.html (visitado el 12 de junio de 2017).

16 Jimena Quesada, L., Sistema europeo de derechos fundamentales, Madrid, Colex, 2006, pp. 38-41.

17 En esa misma fecha entró en vigor, tras su ratificación, para países como Alemania e Islandia que, en cambio, no habían sido signatarios del Estatuto de Londres.

18 Ese enfoque puede comprobarse en diversas contribuciones de la obra de Gordillo PÉrez, L. I. (Dir.), Constitutionalism of European Supranational Courts. Recent developments and challenges, Aranzadi, Cizur Menor, 2015. 
ignorar el creciente impacto de la Carta Social Europea (CSE) — complemento natural del $\mathrm{CEDH}$ - etiquetada como «Constitución Social para Europa» por los máximos dirigentes del Consejo de Europa ${ }^{19}$ y por la doctrina más autorizada en la materia ${ }^{20}$.

A este respecto, que en el Reino Unido no pasa inadvertido ese impacto constitucional de los dos instrumentos fundamentales del Consejo de Europa (CEDH y CSE), lo evidencia, como luego se verá, tanto su posición reticente hacia el CEDH y la jurisprudencia del el TEDH como, paralelamente, su débil o limitada aceptación de la CSE y de la jurisprudencia del Comité Europeo de Derechos Sociales (CEDS).

\section{LA TARDÍA ASUNCIÓN DE LOS ESTÁNDARES BÁSICOS DE LA CULTURA EUROPEA DE LOS DERECHOS}

\subsection{La vacilante incorporación constitucional del Convenio Europeo de Derechos Humanos y sus secuelas}

Como se ha avanzado, diversas circunstancias muestran las reticencias del Reino Unido hacia el CEDH, pese a haber sido uno de los países que lo suscribieron en su origen.

Es verdad que inicialmente fueron recelos compartidos por la mayoría de las Partes Contratantes, lo que resulta incluso lógico y comprensible dado que el CEDH se erigía en el primer instrumento internacional de derechos humanos que daba la posibilidad a los individuos de llevar a un Estado al banquillo ante una instancia jurisdiccional supraestatal. Ello explica que la jurisdicción del TEDH para recibir demandas individuales fuese al principio de aceptación facultativa (a diferencia de la obligada aceptación del mecanismo de demandas interestatales) y que solo tres de los diez primeros Estados Partes en el CEDH (Dinamarca, Irlanda y Suecia) efectuaran las declaraciones previstas para aceptar la competencia de la originaria Comisión Europea de Derechos Humanos para recibir los recursos individuales (art. 25) y la correlativa jurisdicción del TEDH

19 Véase la Opinión del Secretario General del Consejo de Europa sobre la iniciativa de la UE de establecer un Pilar Europeo de Derechos Sociales (Estrasburgo, 2 de diciembre de 2016): «the European Social Charter of the Council of Europe represents an essential component of the continent's architecture of fundamental rights and is therefore seen as the Social Constitution of Europe», https://rm.coe.int/16806dd0bc (acceso el 5 de junio de 2017).

20 Por todos, los trabajos incluidos en DE SCHutTer, O. (Coord.), The European Social Charter: A social constitution for Europe/La Charte sociale européenne: Une constitution sociale pour l'Europe, Bruxelles, Bruylant, 2010. 
(art. 46). Como es sabido, solo con la adopción del Protocolo núm. 11 (en vigor desde noviembre de 1998) desapareció la Comisión, se instituyó el TEDH como único y permanente y, al tiempo, se impuso a todos los Estados Partes el recurso individual sin restricciones ${ }^{21}$.

Ahora bien, en el caso del Reino Unido, más allá de esas iniciales reticencias compartidas, pueden encontrarse al menos tres elementos que revelan su siempre recelosa posición hacia el CEDH y el TEDH.

El primero de ellos lo constituye la tardía incorporación efectiva del tratado a su orden constitucional, mediante la Human Rights Act de 1998 (que obtuvo la sanción real o Royal Assent el 9 de noviembre de 1998 y entró en vigor el 2 de octubre de 2002) ${ }^{22}$.

El segundo elemento tiene que ver con el impulso del Reino Unido para la reforma «a la baja» del TEDH, que se concretó en la Conferencia de Brighton celebrada del 18 al 20 de abril de 2012 en el marco de la presidencia británica del Comité de Ministros del Consejo de Europa. Las propuestas británicas — que fueron presentadas el 23 de febrero de 2012 a través de un proyecto de declaración destinado a servir de base para la discusión en dicha Conferencia- giraron en torno a tres ejes cuyo común denominador consistía en mitigar el alcance el derecho al recurso individual ante el TEDH, aunque sin llegar a ponerlo en

21 Concretamente, ese Protocolo núm. 11 reconocía a los individuos la facultad de intervenir directamente ante el TEDH en todas las fases del procedimiento (locus standi), mientras que previamente el Protocolo núm. 9 (vigente desde octubre de 1994) había reconocido al demandante individual la facultad de someter el caso al TEDH (ius standi) en ese plazo de tres meses desde que la Comisión emitía el informe sobre el fondo del asunto. Sobre dicha evolución, FLAUSS, J. F., «Le droit de recours individuel devant la Cour européenne des droits de l'homme. Le protocole n. ${ }^{\circ} 9$ à la Convention européenne des droits de l'homme», Annuaire français de droit international, vol. 36, 1990, pp. 507-519. El derecho al recurso individual fue calificado por el propio TEDH como «clave de bóveda del mecanismo de salvaguardia de los derechos humanos» en su Sentencia Mamatkulov y Askarov c. Turquía de 4 de febrero de 2005. Sin embargo, tampoco conviene exagerar el potencial de tal derecho dado el exigente filtro de la admisibilidad y dada, asimismo, la sobrecarga de trabajo que soporta el TEDH a causa de los miles de demandas que se le dirigen. Sobre esos riesgos ha advertido Sánchez Patrón, J. M., en «Las condiciones de admisibilidad de las demandas individuales ante el Tribunal Europeo de Derechos Humanos: ¿Un logro en riesgo?», Ordine internazionale e diritti umani, 2014, pp. 284-303.

22 En la guía «A New Era of Rights and Responsibilities - Core Guidance for Public Authorities» preparada por el Ministerio del Interior británico (Home Office) para dar a conocer el Convenio Europeo a todos los funcionarios públicos a través de dicha Ley, puede leerse que para el Ministro del Interior, Mike O’Brien, la Human Rights Act «establece nuevas responsabilidades para todos aquellos que trabajan en el sector público. Tenemos atribuida una función vital en la creación de una nueva cultura de los derechos humanos. Espero que esta Core Guidance sea un valioso instrumento para hacer realidad esa nueva cultura», citado por JimENA QUESADA, L., Sistema europeo de derechos fundamentales, op. cit., p. 32. 
entredicho: a) se pretendía incluir en el texto articulado una referencia a los principios de subsidiariedad y al margen de apreciación, otorgando mayor peso a las autoridades nacionales en detrimento del propio TEDH; b) se propugnaba incrementar el diálogo entre los órganos jurisdiccionales nacionales supremos y el TEDH a través de un mecanismo de consulta similar a la cuestión prejudicial que se suscita ante el TJUE pero sin carácter vinculante; y c) se proponía flexibilizar aún más los criterios de inadmisibilidad de las demandas individuales, así como reducir el plazo de seis meses para la formulación de dichas demandas. Frente a dichas propuestas, el TEDH efectuó observaciones mediante un documento adoptado por el Pleno el 20 de febrero de 2012 en donde, pese a alertar sobre la necesidad de respetar dos condiciones (preservar el derecho al recurso individual y establecer mecanismos nacionales e internacionales susceptibles de tratar las demandas bien fundamentadas que en cambio no pueda tratar el TEDH), suscribía el fin general de hacer «gestionable» el volumen de asuntos sometidos al Alto Tribunal de Estrasburgo ${ }^{23}$. Lo cierto es que la oposición matizada del TEDH, así como la de algunos Estados Miembros del Consejo de Europa (entre ellos, Alemania, Andorra, Austria, Finlandia, Polonia, Rumanía, Croacia, Chipre, Eslovenia o Rumanía), no consiguieron evitar que, en esencia, la proposición británica fuera sostenida por la mayor parte de los socios de la Organización (y con especial entusiasmo por parte de Suiza). En estas condiciones, la Conferencia de Brighton ${ }^{24}$ mostró el peso — euroescéptico- del Reino Unido. De hecho, los Protocolos núm. 15 y núm. 16 vinieron a hacerse eco, básicamente, de las restrictivas propuestas británicas ${ }^{25}$.

23 http://www.echr.coe.int/Documents/2012_Brighton_Opinion_ENG.pdf (acceso el 5 de junio de 2017).

24 Precedida por las asimismo importantes Conferencias de Interlaken (18-19 de febrero de 2010) y de Izmir (26-27 de abril de 2011) y secundada por las de Oslo (7-8 de abril de 2014) y Bruselas (26-27 de marzo de 2015).

25 Y ello tanto en materia de abreviación del plazo de interposición de las demandas y de la mayor laxitud en el examen de la admisibilidad de ellas (en el Protocolo núm. 15, que, sin embargo, acogió las referencias a la subsidiariedad y al margen de apreciación nacional en el preámbulo y no en el texto articulado) como en lo referente al diálogo judicial de resultado no vinculante para las jurisdicciones nacionales supremas (en el Protocolo núm. 16). Sobre los citados Protocolos, véase López Guerra, L., "Los Protocolos de reforma n. ${ }^{\circ} 15$ y 16 al Convenio Europeo de Derechos Humanos», Civitas. Revista Española de Derecho Europeo, núm. 49, 2014, pp. 11-29. En relación con la ausencia formal de vinculatoriedad de la respuesta del TEDH, resulta muy interesante la matización efectuada por el entonces Presidente del TEDH, Dean Spielman, quien entendía que si una Corte suprema nacional se apartara de la opinión de la Corte de Estrasburgo, podría verse ulteriormente desautorizada tras el más que probable registro de una demanda individual y posterior condena, Spielmann, D., Discours du Président Dean Spielmann, Séminaire Tribunal constitution- 
En fin, el tercer elemento que denota hasta qué punto llegan los recelos hacia el CEDH y el TEDH es la simple posibilidad que el Gobierno británico barajó de permanecer en la UE pero denunciar el CEDH y el TEDH — iel instrumento más emblemático del Consejo de Europa y su buque insignia!——26 ${ }^{26}$ lo que habría llevado a derogar la Human Rights Act de 1998 y sustituirla por una nueva British Bill of Righs ${ }^{27}$.

\subsection{La incompleta aceptación de la Carta Social Europea y el impacto del Brexit en los derechos sociales}

De entrada, conviene recordar que, del mismo modo que el CEDH ha sido modificado a través de dieciséis Protocolos, el «sistema» de la CSE está compuesto por la Carta originaria adoptada el 18 de octubre de 1961 en Turín y cuatro modificaciones, a saber: el Protocolo de 1988 (que añadió nuevos derechos), el Protocolo de enmienda de 1991 (sin vigencia formal todavía ${ }^{28}$ ), el Protocolo de 1995 (que establecía el procedimiento de reclamaciones colectivas) y la CSE

nel, Madrid, 22 de mayo de 2015, p. 7, http://www.echr.coe.int/Documents/Speech_20150522_ OV_Spielmann_Tribunal_constitutionnel_Madrid_FRA.pdf

26 Tales fueron, siendo entonces Ministra de Interior, las declaraciones de la Premier británica, Theresa May — que, por cierto, no consiguió la mayoría absoluta para gobernar en las elecciones de 8 de junio de 2017 — en los medios de comunicación, recogidas el 25 de abril de 2016 en la BBC, «UK should quit European Convention on Human Rights», http://www.bbc.com/news/ uk-politics-eu-referendum-36128318 (acceso el 30 de junio de 2017).

${ }^{27}$ Como puede comprobarse, se trata de uno de los cuatro escenarios que se barajaron antes o durante la campaña del referéndum del Brexit: 1. Permanecer en la UE y mantener la Human Rights Act; 2. Permanecer en la UE y derogar la Human Rights Act; 3. Abandonar la UE y mantener la Human Rights Act.; y 4. Abandonar la UE y derogar asimismo la Human Rights Act, Boyle, K. y Cochrane, L., «Brexit and British Bill of Rights: four scenarios for human rights», The UK in a Changing Europe, Research papers, King's College London, 2017 (http://ukandeu. ac.uk/explainers/brexit-and-a-british-bill-of-rights-four-scenarios-for-human-rights/, acceso el 30 de junio de 2017). Por lo demás, tras la victoria del Brexit en el referéndum de 2016, cabe desear que no se opte en algún momento por el cuarto escenario, aunque no pueda descartarse por completo.

${ }^{28}$ El Protocolo de 1991 sigue sin entrar formalmente en vigor al precisar la unanimidad de todos los Estados Partes en la Carta Social, pero su contenido es aplicado en la práctica merced a una decisión del Comité de Ministros del Consejo de Europa de diciembre de 1991, mediante la que se pedía a los órganos de control de la Carta que aplicaran ese Protocolo incluso antes de su entrada en vigor «en la medida en que el texto de la Carta lo permitiere». Así, todas las disposiciones del Protocolo de 1991 son aplicables, excepto la elección de miembros del Comité Europeo de Derechos Sociales por la Asamblea parlamentaria (siguen siendo elegidos por el Comité de Ministros). 
revisada de 1996 (que volvía a ampliar el catálogo de derechos, además de contener una cláusula para aceptar el procedimiento de reclamaciones colectivas ${ }^{29}$ ).

Pues bien, de ese «sistema» europeo de derechos sociales, el Reino Unido fue signatario de la Carta originaria de Turín y la ratificó el 11 de julio de 1962, aceptando 60 de sus 70 párrafos en virtud de un mecanismo de ratificación parcial previsto por el artículo 20 de la propia Carta. Pero la aceptación británica resulta limitada o incompleta no solamente por la utilización de ese mecanismo de asunción «a la carta» (mediante el que se descarta la aplicación de importantes disposiciones $)^{30}$, sino asimismo por mantener su compromiso inicial bajo mínimos pues no ha firmado ni ratificado el Protocolo de 1988 ni el Protocolo de 1995, y ha firmado pero no ratificado el Protocolo de 1991 y la CSE revisada de 1996.

Esa insuficiente aceptación del máximo exponente del constitucionalismo social europeo por parte del Reino Unido es incluso más grave que en el caso de España puesto que, realmente, nuestro país supera el modesto compromiso británico en lo atinente a los Protocolos de 1988 y de 1991 (ambos ratificados por España), teniendo ambos países como asignatura pendiente la aceptación de las dos modificaciones más recientes e importantes. Y no son los únicos: a finales de mayo de 2017, eran 15 los países que habían aceptado el procedimiento de reclamaciones colectivas previsto en el Protocolo de 1995 y 34 las Partes Contratantes de la CSE revisada de $1996^{31}$.

La superación de esas asimetrías en la incorporación del acervo social europeo figura igualmente como uno de los grandes desafíos del conocido como «Proceso de Turín» ${ }^{32}$, que a su vez incitó a la UE a proponer un nuevo «Pilar Europeo

29 La base habilitante es el artículo D de la Carta revisada, incluido en la Parte IV.

30 Concretamente, se descartan los artículos 2.1, 4.3, 7.1, 7.4, 7.7, 7.8, 8.2, 8.3, 8.4, 12.2, 12.3 y 12.4 .

31 Por ello, no sorprende que el Comité de Ministros del Consejo de Europa en la Declaración adoptada en octubre de 2011 con motivo del quincuagésimo aniversario de la CSE de 1961 apelara a la superación de ambas asignaturas pendientes por parte de los Estados Miembros que todavía no hubieran aceptado el Protocolo de 1995 sobre reclamaciones colectivas y la CSE revisada de 1996.

32 Dicho proceso fue lanzado por el Secretario General del Consejo de Europa (en cooperación con la Presidencia semestral italiana del Consejo de la UE y con el Municipio de Turín) e iniciado con la importante Conferencia política de alto nivel celebrada en Turín los días 17-18 de octubre de 2014 para reforzar la efectividad de los derechos consagrados en la Carta Social Europea y las sinergias con la UE. Esa primera Conferencia fue secundada por la posterior Conferencia de alto nivel sobre «El futuro de la protección de los derechos sociales» organizada en Bruselas en febrero de 2015 en el marco de la Presidencia belga del Consejo de Europa, así como por una Conferencia interparlamentaria de los 47 Estados miembros del Consejo de Europa dedicada a la CSE celebrada nuevamente en Turín, en marzo de 2016, y organizada por el Consejo de Europa (en colabora- 
de Derechos Sociales» ${ }^{33}$. Únicamente superándolas se evitará la existencia de una Europa social a varias velocidades y se preservará el carácter indivisible de todos los derechos humanos (subrayado en el Preámbulo de la CSE revisada de 1996). En este sentido, no parece coherente que el Consejo de Europa solo exija la ratificación del CEDH para ser Estado miembro (sin exigencia paralela de aceptación de la $\left.\operatorname{CSE}^{34}\right)$, únicamente obligue a aceptar el conjunto de disposiciones del CEDH (pero no de la CSE, ni siquiera de la revisada de 1996, que sigue previendo el régimen de «ratificación a la carta») y no tenga una política más persuasiva y exigente para la generalización del procedimiento de reclamaciones colectivas ante el CEDS (a semejanza de la que siguió para imponer la generalización del derecho al recurso individual ante el TEDH mediante el Protocolo n. ${ }^{\circ} 11$ al $\left.\mathrm{CEDH}\right)$.

En fin, a la vista del paralelismo entre las dinámicas del Consejo de Europa y de la UE, es muy probable que el Brexit aleje, desafortunadamente, la posibilidad de una mayor implicación del Reino Unido en el sistema de la CSE. Ahora bien, la incompleta e insuficiente aceptación de la CSE y el general desconocimiento de la misma y de la labor del CEDS, a lo que podría añadirse el frecuente y erróneo entendimiento de que la CSE se encuentra en el seno de la UE en vez de en el Consejo de Europa, e incluso la confusión entre la CSE y la Carta comunitaria de derechos sociales fundamentales de los trabajadores de 1989, ha conducido a que aquélla pase bastante desapercibida en el contexto de las discusiones sobre el Brexit. Así las cosas, habrá que reconocer que tal vez todo ello haya evitado el planteamiento de la denuncia de la CSE como alternativa al Brexit (a diferencia, como ya se comentó, de lo ocurrido en relación con el CEDH, precisamente por su alto nivel de aceptación y de conocimiento, lo que es predicable asimismo de la jurisprudencia del TEDH), y ello pese a que los derechos de los trabajadores figuran como uno de los puntos cruciales de la denominada hoja de ruta del Brexit. En cualquier caso, constituye un imperativo insoslayable que el Brexit no acarree un retroceso en el acervo social ya conseguido en el Rei-

ción con la Cámara de Diputados italiana y con el Municipio de Turín). Los documentos más relevantes de dicho proceso pueden encontrarse en la web del Consejo de Europa (http://www.coe. int/en/web/turin-process, acceso el 5 de junio de 2017).

33 Tal como sugirió el Presidente de la Comisión Europea, Jean-Claude Juncker, en su discurso sobre el estado de la UE en el Parlamento Europeo en septiembre de 2015. Véase la Comunicación de la Comisión al Parlamento Europeo, al Consejo, al Comité Económico y Social Europeo y al Comité de las Regiones sobre establecimiento de un pilar europeo de derechos sociales, Bruselas, 24 de abril de 2017, $\operatorname{COM}(2017) 250$ final.

34 De los 47 Estados miembros del Consejo de Europa, 9 están vinculados todavía por la CSE de 1961 y 4 no han aceptado ninguno de los compromisos de la Carta Social, ni siquiera de la originaria: a saber, Liechtenstein, Mónaco, San Marino y Suiza. 
no Unido para adecuarse a las resoluciones del CEDS en materia de protección de menores, de empleo, de libertad de circulación de personas o de no discriminación por diversos motivos (entre otros, nacionalidad, sexo, origen étnico o discapacidad $)^{35}$. Sobre estas cuestiones volveremos después.

\section{LA INICIAL EXCLUSIÓN Y LAS SUCESIVAS EXCEPCIONES BRITÁNICAS A LA EUROPA COMUNITARIA DE LOS DERECHOS}

\section{La EFTA y la promoción de la Europa integrada de los derechos, sin integrarse en ella}

Si en el caso del Consejo de Europa, como se ha visto, el Reino Unido ha sido promotor de esa Europa amplia de los derechos formando parte de la misma -aunque, al tiempo y paradójicamente, se ha mostrado reticente y receloso hacia los dos tratados europeos más emblemáticos del sistema de Estrasburgo, el CEDH y la CSE_- en el supuesto de la Europa integrada o comunitaria de los derechos desempeñó el extraño rol de promotor externo o ajeno, es decir, desde fuera, manteniéndose al margen de la fundación en 1951 de las Comunidades Europeas. Recordemos, en este sentido, la voluntad «federal» expresada por Churchill en su discurso de 1946 en Zurich: los «Estados Unidos de Europa»...

Pero Reino Unido no solo se quedó al margen sino que lanzó la propuesta de crear una zona de libre cambio como alternativa y contrapeso a la Comunidad Económica Europea, lo que se concretó en la firma el 4 de febrero de 1960 en Estocolmo del Convenio que creó la Asociación Europea de Libre Cambio, más conocida como EFTA (European Free Trade Association), en la que se embarcaron junto al Reino Unido otros seis países: Austria, Dinamarca, Noruega, Portugal, Suecia y Suiza (a los que se sumarían Finlandia en 1961, Islandia en 1970 y Liechtenstein en 1991). Por supuesto, la EFTA es menos ambiciosa que la UE desde una perspectiva tanto económica como política con la consiguiente menor grado de afectación de la soberanía de los Estados que la integran ${ }^{36}$ y ha ido perdiendo relevancia a la vez que miembros en beneficio de la segunda. Por ello

35 Véase la «ficha por país» relativa al Reino Unido sobre la Carta Social Europea, especialmente el apartado II («Ejemplos de progresos realizados en el cumplimiento de los derechos establecidos en la Carta»), https://rm.coe.int/1680644aa9 (acceso el 5 de junio de 2017), pp. 6-7.

36 Como es sabido, en el plano económico, persigue más una cooperación comercial que una unión aduanera, y en el político, su modesta estructura organizativa se apoya en un Consejo formado por todos los representantes de los Estados miembros, que adoptan las decisiones por unanimidad, y asistido por una serie de órganos consultivos y administrativos integrados por apenas un centenar de personas. 
siempre mantuvieron una relación complicada. Así, en el propio Preámbulo del Convenio EFTA de 1960 se apelaba a la remoción de barreras comerciales y a la promoción de una cooperación económica más estrecha con los Estados Miembros de la CEE. Más tarde, sobre la base de la idea de Jacques Delors de avanzar en la integración entre la CEE y la EFTA, se adoptó en 1992 el Acuerdo sobre el Espacio Económico Europeo (EEE): en la actualidad, forman parte de ese Acuerdo del EEE entre la UE y la EFTA los 28 socios comunitarios y tres de los cuatro países miembros de la EFTA (Islandia, Liechtenstein y Noruega pues Suiza rechazó en 1992 mediante referéndum su integración en el EEE, disciplinando sus relaciones con la UE mediante acuerdos bilaterales).

Si bien en los primeros apartados del Preámbulo de dicho Acuerdo de 1992 las Partes Contratantes se muestran convencidas «de la contribución que un EEE aportará a la construcción de una Europa basada en la paz, la democracia y los derechos humanos», y reafirman «la absoluta prioridad concedida a una relación privilegiada entre las Comunidades Europeas, sus Estados miembros y los Estados de la EFTA, basada en la proximidad, los valores comunes duraderos y la identidad europea», para «contribuir, sobre la base de una economía de mercado, a la liberalización y cooperación comercial a escala mundial», esas afirmaciones «integradoras» se compensan con otras más defensoras de la propia soberanía consistentes en considerar que el objetivo de las Partes Contratantes se abordará «en pleno respeto de la independencia de los tribunales»y sin restringir «la autonomía para la toma de decisiones ni el poder de celebrar los Tratados de las Partes Contratantes».

Por si cupiese alguna duda sobre esto último, en la web oficial de la EFTA se subraya que a través del Acuerdo de 1992, los Estados «no han transferido competencias legislativas algunas a las instituciones del EEE y no están legitimados, constitucionalmente, para aceptar decisiones de la Comisión o del Tribunal de Justicia», añadiéndose que en dicho marco EFTA-EEE «todas las decisiones son adoptadas por consenso, a diferencia de la UE en donde las decisiones relativas a la legislación del EEE son normalmente adoptadas por mayoría».

Tras el Brexit, se plantea si el Reino Unido puede retornar a la EFTA, pero parece una opción difícil precisamente por esa relación que se mantiene con la UE y que ha permitido fraguar bastantes acuerdos e incluso incorporar legislación comunitaria por parte de los países de la EFTA (legislación, por cierto, que ahora el Reino Unido pretende ir derogando paulatinamente). Y, además, socios significativos de la EFTA como Noruega no ven con buenos ojos ese rein- 
greso del Reino Unido ${ }^{37}$. Un extraño retorno que, de producirse, seguramente seguiría una dinámica parecida a la de Suiza.

De cualquier modo, un acuerdo bilateral del Reino Unido análogo al suscrito por Suiza con la UE se aventura complejo en estos momentos; cuando menos un acuerdo autónomo con respecto a las negociaciones del Brexit que se han acometido sobre la base del artículo 50 TUE, máxime cuando dicho acuerdo ya se intentó con Cameron con carácter previo (en febrero de 2016) ${ }^{38}$ al referéndum del Brexit de 23 de junio de 2016, precisamente como última oportunidad de evitar esa salida británica de la UE con la que de manera irresponsable decidió especular electoralmente el propio Cameron.

Al final, no debe sorprender la desconfianza en el seno de la EFTA hacia el reingreso del Reino Unido, por lo que posiblemente pudiera prosperar otra opción más modesta (y más acorde con la pretendida posición de superioridad y

37 Véase «Tras el Brexit, la EFTA es una opción para el Reino Unido, pero Noruega se opone a su entrada», El Economista del 1 de julio de 2016, http://www.eleconomista.es/economia/ noticias/7677327/07/16/Tras-el-Brexit-la-EFTA-es-una-opcion-para-el-Reino-Unido-peroNoruega-se-opone.html (visitado el 7 de junio de 2017): «Noruega quiere mantener su posición. Monica Maeland, ministra de Industria de Noruega, explica a Bloomberg que «son los británicos los que tienen que aclarar su posición en este momento... Además, la UE tiene que decidir cómo quiere que sea esa nueva relación, a partir de ahí nosotros decidiremos nuestra posición. Es demasiado rápido para hablar sobre una expansión de la EFTA. Aunque pertenecer a la EFTA es una vía sencilla para tener acceso libre al comercio con la UE, esta no se encuentra exenta de costes. Por ejemplo, Noruega ha tenido que adoptar el 75\% de las leyes que se aprueban en la UE, aunque no ha tenido voz ni voto para negociarlas. Además, la EFTA paga 860 millones de euros al año por tener ese privilegio de comerciar con libertad con la UE sin formar parte de ella».

38 Ese Acuerdo se recoge en la Decisión de los Jefes de Estado o de Gobierno, reunidos en el seno del Consejo Europeo, relativa a un nuevo régimen para el Reino Unido en la UE, que figura como Anexo I a las Conclusiones del Consejo Europeo de los días 18 y 19 de febrero de 2016. Dicho acuerdo contiene un lamentable conjunto de propuestas asimétricas «a la baja» para satisfacer al Reino Unido, bastando leer el siguiente párrafo para percatarse de ello: «recordando que los Tratados, junto con las referencias al proceso de integración europea y al proceso creador de una unión cada vez más estrecha entre los pueblos de Europa, contienen también disposiciones específicas según las cuales algunos Estados miembros tienen el derecho de no participar o están exentos de la aplicación de determinadas disposiciones o capítulos de los Tratados y del Derecho de la Unión que afectan a cuestiones como la adopción del euro, a decisiones que tienen repercusiones en el ámbito de la defensa, a la realización de controles fronterizos de personas, así como a medidas en el espacio de libertad, seguridad y justicia. Determinadas disposiciones de la Unión permiten asimismo que uno o varios Estados miembros no participen en medidas destinadas a impulsar los objetivos de la Unión, en particular mediante el establecimiento de cooperaciones reforzadas. Dichos procesos posibilitan, por lo tanto, distintas vías de integración para los diferentes Estados miembros, permitiendo a los que deseen ahondar en la integración avanzar, al tiempo que respeta el derecho de los que no desean seguir ese rumbo (...)», http://www.consilium.europa. eu/es/press/press-releases/2016/02/19-euco-conclusions/ (visitado el 7 de junio de 2017). 
los recelos soberanistas británicos) que radicara en un acuerdo de libre comercio de la EFTA con el Reino Unido similar al que dicha organización mantuvo (por ejemplo, con España antes de que ingresara en las Comunidades Europeas) o mantiene con otros países (como Turquía o Corea del Sur).

Tampoco ha tenido el Reino Unido una relación pacífica con la UE cuando ha formado parte de la misma. Recuérdese, frente a la Unión Económica y Monetaria, la lapidaria frase de Margaret Thatcher «I want my money back» ${ }^{39}$ y el famoso «cheque británico» acordado en 1984. O el discurso de la propia «Dama de Hierro» ante la Cámara de los Lores en 1990 cuando ironizó sobre una posible moneda única a propósito del funcionamiento del entones ECU (European Currency Unit) y la posición británica contraria al Euro con motivo de su consagración a través del Tratado de Maastricht... Cuántas veces los líderes británicos han utilizado electoralmente la pertenencia a la UE, bien prometiendo que iban a someter a referéndum cada importante reforma de los Tratados comunitarios ${ }^{40}$, bien oponiéndose al candidato propuesto para presidir la Comisión Europea, la institución comunitaria considerada motor de integración ${ }^{41}$.

Naturalmente, el Reino Unido ha ejercido su soberanía abandonando la UE, optando por la solución más radical para eludir los embates de la globalización económica al principio democrático, un déficit que clásicamente afecta al propio sistema institucional comunitario. La solución no deja por ello de ser tanto más paradójica cuanto que el Reino Unido es indudablemente el socio comunitario que se ha visto menos afectado por la dinámica de sometimiento del poder político al poder económico en el seno de la UE ${ }^{42}$.

39 Frase pronunciada en Dublín el viernes 30 de noviembre de 1979 con motivo de la cumbre de Jefes de Estado y de Gobierno (el actual Consejo Europeo) y que comportó una de las mayores crisis de la historia de la construcción europea. Véase sobre dicho impacto el artículo de Fralon, J. A., «Margaret Thatcher: I want my money back», Le Monde, 11 de mayo de 2005, http://www.lemonde.fr/europe/article/2005/05/11/30-novembre-1979-margaret-thatcher-i-wantmy-money-back_648386_3214.html (visitado el 2 de junio de 2017).

40 Pueden encontrarse ejemplos de dicha utilización en FABRE, C.: «Royaume-Uni et UE: plus de 40 ans de relations dévoilées «, Le Taurillon, 25 de enero de 2013 (https://www.taurillon. org/Royaume-Uni-et-UE-plus-de-40-ans-de-relations-devoilees,05499, visitado el 16 de julio de 2017).

41 Así, John Major vetó la candidatura de Jean Luc Dehaene (considerado como excesivamente «federalista»), Tony Blair se opuso a Guy Verhofstadt y David Cameron desaprobó la elección del presidente actual, Jean-Claude Juncker.

42 Sobre estas cuestiones, García Guerrero, J. L. y Martínez Alarcón, M. L., «Constitución y mercado en la crisis de la Unión Europea: consideraciones preliminares», Estudios de Deusto, vol. 64, n. ${ }^{\circ}$ 1, 2016, pp. 15-21. Los autores se plantean si la solución a estos problemas se encuentra en una mera reforma de los mecanismos de integración o si por el contrario resulta inevitable desembocar en una Europa Federal. 
En última instancia, siendo tristemente insolidaria la postura del Reino Unido, parece casar bien con la idiosincrasia británica ${ }^{43}$. Claro que quizá hubiera resultado más coherente no ingresar en la Europa comunitaria que hacerlo influyendo de manera determinante en su diseño ulterior (como bloque económico y político y, transversalmente, como espacio común de derechos y libertades) para acabar abandonándola ${ }^{44}$.

\section{Las excepciones parciales sobre derechos en las reformas de los Tratados europeos}

Una vez incorporado el Reino Unido a la Europa comunitaria en 1973 no tardaron en aparecer los clásicos recelos y reticencias británicos, manifestándose con ocasión de las reformas fundamentales de los tratados y de los instrumentos comunitarios más significativos en materia de derechos humanos.

En efecto, la primera gran reforma de los Tratados constitutivos se articuló a través del Acta Única Europea de 1986, que contenía por vez primera una referencia, en su Preámbulo (por tanto, con carácter prevalentemente programático, al no incluirse en el texto articulado), a los dos tratados más emblemáticos del Consejo de Europa (el Convenio Europeo de Derechos Humanos de 1950 y la Carta Social Europea de 1961) junto a «los derechos fundamentales reconocidos en las Constituciones y leyes de los Estados miembros», para «promover conjuntamente la democracia», así como «la libertad, la igualdad y la justicia social». Se subrayaba en el mismo Preámbulo la convicción de los Estados miembros, entre ellos el Reino Unido, sobre la importancia para los pueblos democráticos europeos de «la idea europea, los resultados logrados en los ámbitos de la integración económica y de la cooperación política, así como la necesidad de nuevos desarrollos», entre ellos «la responsabilidad que incumbe a Europa de procurar adoptar cada vez más una postura uniforme y de actuar con cohesión y solidaridad». Semejantes cohesión y solidaridad entre las sociedades de los Esta-

43 De interés resultan en tal sentido las aportaciones incluidas en la obra de OUTHWAITE, W. (Ed.), Brexit. Sociological Responses, London, Anthem Press, 2017. Así, por ejemplo, apunta WESTLAKE, M. que si el Reino Unido hubiera respondido positivamente a la Declaración Schuman de 1950 o a los Tratados constitutivos (primero en 1951 para la CECA y luego en 1957 para la CEE y la EURATOM), seguramente no se hubiera llegado a plantear nunca el referéndum sobre el Brexit, «The increasing inevitability of that referéndum», p. 3.

44 «Réflexion sur le Brexit», L'Europe des citoyens, http://www.leuropedescitoyens.org/rflexionsur-le-brexit (acceso el 20 de mayo de 2017). 
dos miembros de la UE siguen siendo imprescindibles para forjar la prosperidad de la nueva Europa integrada ${ }^{45}$.

Precisamente en conexión directa con esos elementos compartidos (libertad, igualdad, justicia social, cohesión y solidaridad) una importante novedad del Acta Única, ya en el texto articulado, fue la introducción de disposiciones tendentes a compensar el componente mercantilista del mercado interior con una dimensión social ${ }^{46}$, especialmente en el terreno de la protección de la seguridad y la salud en el trabajo y del diálogo social ${ }^{47}$. Interesantes disposiciones (que se sumaban a las cuatro clásicas libertades económicas referentes a la libre circulación de capitales mercancías, personas y servicios y, sobre todo, a la igualdad de remuneración entre sexos y al disfrute de los beneficios de la seguridad social que se incluyeron en el Tratado constitutivo de la CEE) que, obviamente, no dejaban de ser modestas. Por tal motivo, no resulta extraño que los Estados miembros decidieran ahondar en esa dimensión mediante la Carta comunitaria de derechos sociales fundamentales de los trabajadores de 1989 como instrumento programático. En cambio, sorprende que Reino Unido fuese el único de los entonces doce socios comunitarios que no suscribiera dicha Carta — lo hizo tardíamente en 1997-lo que contrastaba con la condición de Parte Contratante de la Carta Social de 1961 (obligatoria como tratado internacional).

Semejante postura británica solo se entiende — sin justificarla— si se pone en conexión la relevancia de los derechos y libertades con la paulatina dimensión político-constitucional de la UE rechazada por el Reino Unido (y otros socios comunitarios), observándose que el citado Preámbulo del Acta Única se refiere, no por casualidad, a la «integración» económica y a la «cooperación» política. Como tampoco es casual que la segunda gran reforma de los Tratados comunitarios, el Tratado de la UE de Maastricht de 1992, se refiriera a la Unión Económica y Monetaria (UEM) sin llegar a hablar de «unión política» ${ }^{48}$.

45 Janning, J., «Making sense of Europe's cohesion challenge», en Keeping Europeans Together. Assessing the State of EU Cohesion (Ed. Janning, J.), London, European Council of Foreign Relations, 2016, p. 11-12.

46 Sobre la concreta contribución de la dimensión social al Acta Única Europea, véase JoERGES, Ch. y RodL, F., «Informal Politics, Formalised Law and the "Social Deficit" of European Integration: Reflections after the Judgments of the ECJ in Viking e Laval», European Law Journal, Volume 15, Issue 1, 2009, p. 4 ss.

47 Los entonces nuevos artículos 118A y 118B del Tratado CEE.

48 Un excelente resumen de ese desafío británico en Mariscal, N., Más allá de Lisboa: Horizontes europeos, Madrid, Tecnos, 2010, p. 224: «Ha sido el Reino Unido el que ha liderado exitosamente la oposición a la federalización de la integración europea: desde el Congreso de Europa de la Haya de 1948 y el nacimiento un año después en Londres del Consejo de Europa, pasando por la creación de la EFTA como alternativa a las Comunidades Europeas, haciendo desaparecer cual- 
A propósito del Tratado de Maastricht, el Reino Unido hizo valer una vez más un «opt-out» o cláusula de exención en materia de derechos sociales, obligando a los socios comunitarios a dejar fuera del texto articulado ámbitos importantes (relativos, entre otros, a condiciones laborales, información y consulta de los trabajadores, igualdad de oportunidades en el mercado de trabajo y en el empleo entre mujeres y hombres, o la integración de personas excluidas del mercado laboral), que tuvieron que ser reconducidos al Acuerdo sobre política social anejo al Tratado sin la participación británica. Se acordó que dichas materias fueran susceptibles de ser reguladas mediante mayoría cualificada, mientras otras siguieron sometidas a la regla de la unanimidad (entre ellas, seguridad social y protección social de los trabajadores, protección de los trabajadores en caso de despido, o condiciones de empleo de nacionales de terceros países residiendo legalmente en el territorio comunitario).

Hubo que esperar a la siguiente gran reforma, el Tratado de Ámsterdam de 1997, para que el Acuerdo sobre Política Social de Maastricht quedara incorporado al texto articulado y, por ende, con efectos asimismo vinculantes para el Reino Unido. Además, el Tratado de Ámsterdam incorporó nuevos motivos de Derecho antidiscriminatorio (algunos de los cuales — edad, discapacidad u orientación sexual - , por cierto, han tenido un impacto nada desdeñable en el Reino Unido a través de la jurisprudencia del $\mathrm{TJUE}^{49}$ ) y una cláusula de igualdad material que propiciaba la adopción de medidas positivas, así como una referencia a la Carta Social Europea en el entonces artículo 117 del Tratado de la Comunidad Europea (actual art. 151 TFUE). Por consiguiente, a este último respecto, la desvinculación indirecta provocada por el Brexit con respeto a la Carta Social del Consejo de Europa dejará ya de ser solamente «programática».

De todos modos, tanto el Tratado de Ámsterdam como el posterior Tratado de Niza de 2001 mantuvieron la regla de la unanimidad en los ámbitos referidos del Acuerdo sobre política social de Maastricht. En el supuesto del Tratado de Niza, instituyó el Comité de Protección Social e incidió en el conocido «método

quier adjetivación federal en los Tratados que se sucedieron entre 1992 y finalmente logrando erosionar el proceso constitucional del decenio 2000-2009. Los intereses propios del Reino Unido, que con inigualable habilidad y éxito ha sabido promocionar durante siglos, no han coincidido y tampoco hoy coinciden necesariamente con los de Europa. Su respetable opción antifederal, que realmente encubre el rechazo a cualquier unión política de Europa, mientras practica su special relationship con esa exitosa federación que es Estados Unidos, no debe impedir a otros Estados y ciudadanos europeos comprometerse en un proceso cuyo horizonte sea la federación como forma de unión política».

49 A título de ejemplo, véase la STJUE de 17 de julio de 2008, caso Coleman (asunto C-303/06) con origen en la cuestión prejudicial planteada por el Employment Tribunal, London South (Reino Unido). 
abierto de coordinación» que, en cualquier caso, no dejaba de ser un instrumento de acercamiento normativo «programático» (soft-law) y, en consecuencia, visto con menor recelo desde la óptica británica. Como es sabido, con no menos buenos ojos se vio desde el Reino Unido el rechazo de la Carta de los Derechos Fundamentales $^{50}$.

Por último, la doble gran aportación del Tratado de Lisboa de 2007 en este terreno fue haber reconducido esas materias afectadas por la unanimidad a su regulación mediante el procedimiento legislativo ordinario (anterior co-decisión), además de poner al mismo nivel que los Tratados y otorgar fuerza vinculante a la CDFUE, con la lamentable exclusión respecto de este amplio catálogo por parte del Reino Unido (secundado simultáneamente por Polonia y después por la República Checa). Como se explicará a continuación, la exclusión británica de la CDFUE implica una inaceptable especie de enmienda a la totalidad pero, además, revela una clara incongruencia, pues esos derechos sociales del Acuerdo sobre política social de Maastricht que acabó asumiendo mediante los Tratados de Ámsterdam y de Niza (asunción culminada con el propio Tratado de Lisboa $^{51}$ ) son los que se encuentran reconocidos en el catálogo de la CDFUE (básicamente bajo la rúbrica de la «solidaridad» del Título IV).

\section{La enmienda a la totalidad a la Europa de los derechos: el rechazo a la Carta de los Derechos Fundamentales de la Unión Europea}

El Brexit, como retirada total de la UE, no debería sorprender demasiado desde el punto de vista político si consideramos que la propia exclusión de la CDFUE al adoptarse el Tratado de Lisboa ya suponía una inasumible enmienda a la totalidad a la Europa de los derechos ${ }^{52}$, lo que equivaldría a un rechazo a «la sustancia constitucional» de la UE como tal, a una suerte de verdadero Brexit anticipado.

50 Rechazo contundentemente criticado en la doctrina, entre otros por Douglas-ScOTT, S., en «Fundamental Rights, Not Euroscepticism: Why the UK Should Embrace the EU Charter of Fundamental Rights», The UK and European Human Rights: A Strained Relationship?, Ziegler, K.

S., Wicks, E. y Hodson, L. (Eds.), Hart Publishing, Oxford, 2015, p. 249.

51 En el marco, cierto es, de un difícil equilibrio distributivo de competencias sociales, como ha advertido LörCHER, K., en «Social Competences», The Lisbon Treaty and Social Europe, ScHÖMAN, I., LÖrCHER, K. y BruUn, N. (eds.), Hart Publishing, Oxford, 2012, p. 165.

52 Tal crítica en Jimena Quesada, L. y Tajadura Tejada, J., «La prehistoria y la historia del Derecho constitucional europeo (ensayo de paralelismo con el decurso del Derecho constitucional nacional)», Revista de Derecho Político, n. ${ }^{\circ}$ 94, 2015, en particular, pp. 32-47. 
Además, el «opt-out» británico respecto de la CDFUE resultaba inaceptable jurídicamente y creaba una enorme inseguridad jurídica ${ }^{53}$, tanto en clave de Derecho constitucional europeo como de Derecho internacional.

En cuanto al primero, si el Tratado de Lisboa se caracterizó por rescatar sustancialmente el fallido Tratado por el que se establece una Constitución para Europa de 2004, esto es, lo concerniente a lo más materialmente constitucional (el catálogo de derechos fundamentales descartado con anterioridad por el Tratado de Niza $)^{54}$, el «out-put» británico dejaba desprovista de esencia a la Constitución material de la Unión Europea (que, cuando menos, tiene una «sustancia constitucional híbrida» ${ }^{55}$ ). De este modo, no solo se abría paso una perversa dinámica de la «Europa a varias velocidades», sino que se asestaba un duro golpe a la vocación federal que impregnó la Declaración Schuman de $1950^{56}$.

Respecto del segundo, dado que la CDFUE se elevaba, al formar parte del Tratado de Lisboa, a la categoría de Derecho primario u originario, parece obvio que la excepción británica podía indudablemente calificarse como una reserva contraria al objeto y al fin del propio Tratado de Lisboa. La cual, como se ha argumentado, tendría inexorablemente que ser consideraba como inefectiva ${ }^{57} \mathrm{o}$ inútil ${ }^{58}$, por tratarse de una excepción heterogénea que casa mal con las tradiciones constitucionales comunes de los Estados miembros ${ }^{59}$, así como con las

53 Se ha esgrimido así que dicho Protocolo n. ${ }^{\circ} 30$ genera una gran inseguridad jurídica: DE SChutTer, O., «Les droits fondamentaux dans l'Union européenne», Journal de droit européen, n. ${ }^{\circ} 148,2008$, p. 127.

54 Véase Aldecoa Luzarraga, F., y Guinea Llorente, M., «El rescate sustancial de la Constitución Europea a través del Tratado de Lisboa: la salida del laberinto», en Real Instituto Elcano de Estudios Internacionales y Estratégicos, Documento de trabajo/Working Paper n. . 9/2008.

55 Bar Cendón, A., «La Unión Europea: de la Economía a la Política, pasando por el Derecho», Teoría y Realidad Constitucional, n. ${ }^{\circ} 32$, 2013, p. 10. Con tal filosofía, más ampliamente Alegre Martínez, M. A. y Jimena Quesada, L., Fundamentos Constitucionales de la Unión Europea, Madrid, Biblioteca Nueva, 2006, especialmente el capítulo de conclusiones («La razón de ser del Tratado constitucional: ¿Un orden constitucional europeo sin Constitución europea?»), pp. 259-298.

56 A propósito de los efectos que una declaración de derechos puede generar en clave federal, Biglino Campos, P., «Derechos Fundamentales y Competencias de la Unión: el argumento de Hamilton», Revista de Derecho Comunitario Europeo, n. ${ }^{\circ}$ 14, 2003, p. 46.

57 Fernández Tomás, A. F., «La Carta de Derechos Fundamentales de la Unión Europea tras el Tratado de Lisboa. Limitaciones a su eficacia y alcance generadas por el Protocolo para la aplicación de la Carta al Reino Unido y Polonia», en Martín y PÉrez de Nanclares, J. (Coord.), El Tratado de Lisboa: la salida de la crisis constitucional, Iustel, Madrid, pp. 119-149.

58 ZiLler, J., Il nuovo trattato europeo, Il Mulino, Bologna, 2007, p. 177.

59 Bellamy, R., Judicial review in review: A four part-defense of the legal constitutionalism. A review essay on Political Constitutionalism, Cambridge, Cambridge University Press, 2007, p. 50. 
jurisprudencias del TEDH y del $\mathrm{TJUE}^{60}$ en las que la propia CDFUE tiene su fuente de inspiración ${ }^{61}$.

Sobre este último punto, al margen de lo ya expuesto sobre la incoherencia en materia de derechos sociales (los cuales se contienen en el texto articulado del TFUE pero se descartan en la «versión CDFUE»), el Gobierno británico ha llegado a justificar el Brexit como una oportunidad para abandonar la controvertida Carta de Derechos Fundamentales que ha sido acusada de obstaculizar la lucha contra el crimen y el terrorismo, especialmente a causa de la jurisprudencia del Tribunal de Justicia de Luxemburgo y a las sinergias sobre esta cuestión con el Tribunal de Estrasburgo ${ }^{62}$. No extraña, por tanto, que el Tribunal de Justicia sea uno de los principales objetivos en el punto de mira del Brexit, como más tarde se analiza.

De hecho, las inconsistencias de la excepción británica se revelan aún más flagrantes si se repara en que la CDFUE no establece ningún mecanismo específico de supervisión ${ }^{63}$, pero correlativamente algunas jurisdicciones nacionales y europeas ya se habían inspirado en la CDFUE (justamente para reafirmar el acervo europeo ya existente en materia de derechos fundamentales) incluso antes de convertirse en texto vigente en diciembre de 2009; por tal motivo, la cláusula británica de exclusión estaría desprovista de sentido en términos jurídicoprácticos $^{64}$.

También en el plano normativo se percibiría análoga incoherencia, puesto que si las instituciones políticas de la UE (Comisión, Parlamento y Consejo)

60 Cartabia, M., «L'universalità dei diritti umani nell'età dei nuovi diritti», Quaderni costituzionali, n. 3,2009 , p. 544.

61 Así lo establece explícitamente su Preámbulo, donde se reafirman, «dentro del respeto de las competencias y misiones de la Unión, así como del principio de subsidiariedad, los derechos que emanan, en particular, de las tradiciones constitucionales y las obligaciones internacionales comunes a los Estados miembros, del Convenio Europeo para la Protección de los Derechos Humanos y de las Libertades Fundamentales, las Cartas Sociales adoptadas por la Unión y por el Consejo de Europa, así como de la jurisprudencia del Tribunal de Justicia de la Unión Europea y del Tribunal Europeo de Derechos Humanos».

${ }^{62}$ Lo recordaba el editorialista político de The Daily Mail (Jason Groves) el 30 de marzo de 2017, http://www.dailymail.co.uk/news/article-4366156/Charter-Fundamental-Right-set-ditched-Brexit.html (acceso el 20 de mayo de 2017).

${ }^{63}$ El déficit de garantías jurisdiccionales en el sistema de la CDFUE ha sido criticado por Rallo Lombarte, A., en «Las garantías jurisdiccionales de los Derechos Fundamentales reconocidos en la Carta de los Derechos Fundamentales de la Unión Europea», Comentarios a la Constitución Europea (Dirs. Álvarez Conde, E., y Garrido Mayol, V.), libro II, Valencia, Tirant lo Blanch/Consejo Jurídico Consultivo de la Comunitat Valenciana, 2004, pp. 1629-1652.

64 Díez-Picazo, L. M., «Glosas a la nueva Carta de Derechos Fundamentales de la UE», Tribunales de Justicia, n. ${ }^{\circ}$ 5, 2001, p. 26. 
deben legislar atendiendo a la CDFUE $^{65}$ — basta comprobar el gran número de Reglamentos y de Directivas, así como otros actos jurídicos de la UE, típicos y atípicos, que se inspiran y mencionan la CDFUE_-, no resulta comprensible el descarte de la CDFUE como Derecho primario y, en cambio, someterse al carácter obligatorio de las fuentes de Derecho secundario o derivado basadas en aquélla.

\section{LA HOJA DE RUTA DEL BREXIT COMO ABANDONO DEL ORDEN CONSTITUCIONAL EUROPEO DE LOS DERECHOS}

\section{El distanciamiento respecto al catálogo europeo de derechos}

La hoja de ruta del Brexit, desde la perspectiva británica para acometer las negociaciones con la UE en el marco del artículo 50 TUE, viene marcada por el Libro Blanco presentado al Parlamento Británico por la Primera Ministra Theresa May en febrero de $2017^{66}$. En él figuran doce secciones en las que se abordan las prioridades del Reino Unido que habrían informado la decisión del Brexit, a saber: 1) proporcionar seguridad jurídica y claridad para las empresas, el sector público y el público en general; 2) tomar el control sobre las propias leyes poniendo fin a la jurisdicción del TJUE en el Reino Unido; 3) reforzar la unidad entre las cuatro partes del Reino Unido; 4) proteger los lazos históricos con Irlanda manteniendo la zona común de tránsito o «Common Travel Area»; 5) controlar la inmigración, incluyendo la relativa a los nacionales de la UE que vienen al Reino Unido; 6) reforzar en la medida de lo posible los derechos de los ciudadanos de la UE que ya se encuentren en el Reino Unido y de los nacionales británicos que se encuentren en los otros Estados miembros; 7) proteger los derechos de los trabajadores británicos; 8) asegurar libre comercio con los mercados europeos sin pertenecer al Mercado Único; 9) negociar nuevos acuerdos comerciales bilaterales con otros países; 10) asegurar que el Reino Unido siga

${ }^{65} \mathrm{La}$ CDFUE se ha configurado como un elemento transversal para el desarrollo del conjunto de actividades de la UE, especialmente de las legislativas, tal como se propugna en el Report on compliance with the Charter of Fundamental Rights in the Commission's legislative proposals: methodology for systematic and rigorous monitoring [Committee on Civil Liberties, Justice and Home Affairs, Rapporteur: Johannes Voggenhuber, European Parliament, 12.2.2007 (Session document, FINAL A6-0034/2007)].

66 British Government's official «Brexit White Paper», bajo el título The United Kingdom's exit from and new partnership with the European Union, https://www.gov.uk/government/uploads/ system/uploads/attachment_data/file/589189/The_United_Kingdoms_exit_from_and_partnership_with_the_EU_Print.pdf (descargado el 5 de marzo de 2017). 
siendo el mejor lugar para la ciencia y la innovación; 11) cooperar en la lucha contra el crimen y el terrorismo; y 12) proceder a una salida tranquila y ordenada de la UE.

Como cabe apreciar fácilmente, esas doce prioridades para la fase «postBrexit» se encuentran en conexión directa o indirecta con un claro distanciamiento del catálogo europeo de derechos que había quedado desgraciada e inexorablemente anticipado por el Protocolo de exclusión (n. $\left.{ }^{\circ} 30\right)$ de la CDFUE anejo al Tratado de Lisboa. O, mejor dicho, se pretenden eludir los estándares europeos sobre derechos fundamentales, acordes especialmente con la evolución de la ciudadanía de la UE, para poner el énfasis en la titularidad «nacional» de tales derechos evitando la estandarización continental en el Reino Unido; se da con ello la espalda a una de las claves del constitucionalismo multinivel europeo, que reside en articular los diversos estándares de protección en materia de derechos fundamentales ${ }^{67}$.

Así, tal es el objetivo que marca la sección 1 cuando habla de la «Gran Ley de Derogación» («Great Repeal Bill»), mediante la cual se mantendrá el «acervo» comunitario ya asumido en el Reino Unido cuando convenga a las empresas, a las administraciones y al público británicos: con ello se pretende preservar «los derechos y obligaciones que ya existen en el Reino Unido con arreglo a la legislación de la UE y proporcionar una base segura para futuros cambios en nuestra legislación nacional». En conjunción con ello, atendiendo a la sección 2, se quiere blindar la acción de los legisladores (estatal y territoriales) y de los órganos jurisdiccionales británicos frente a la «interferencia» que hasta ahora habrían provocado los actos legislativos y las decisiones judiciales procedentes de la UE. En realidad, la Great Repeal Bill, lo mismo que su posterior versión como European Union (Withdrawal) Bill (publicada el 13 de julio de 2017) ${ }^{68}$, no parecen dejar claro qué papel van jugar las Directivas en el escenario jurídico nacional

67 Freixes SanjuÁn, T., «Els drets fonamentals en perspectiva multinivell. Reflexions entorn dels seus efectes», Revista catalana de dret públic, n. ${ }^{\circ}$ 50, 2015, p. 41. A este respecto, al analizar de manera específica el caso español, como ha apuntado acertadamente VIDAL PrADO, C., «hay una abundancia de catálogos de derechos, tanto a escala nacional como internacional», pero «el elemento clave sigue residiendo en el nivel de garantías ofrecido por cada Estado en su propio territorio. La eficiencia de la protección internacional de los derechos continuará dependiendo de las garantías internas estatales», en «Multilevel Protection of Fundamental Rights in Europe: The Case of Spain», Common European Legal Thinking (Eds. Blanke, H. J., Cruz Villalón, P., Klein, T., y Ziller, J.), Berlin/Heidelberg, Springer, 2015, p. 169.

68 En el momento de cerrar el presente trabajo, el Proyecto de Ley de Retirada de la Unión Europea había superado una primera votación en la Cámara de los Comunes el 11 de septiembre de 2017, por 326 votos a favor y 290 en contra, debiendo seguir su aprobación parlamentaria hasta su aprobación definitiva. 
británico tras el Brexit ${ }^{69}$, moviéndose en un delicado equilibrio entre cambio constitucional y continuidad jurídica ${ }^{70}$.

El argumento central en ambas secciones ( 1 y 2 ) no puede ser de lo más peregrino, pues parece como si las leyes y las resoluciones judiciales británicas no pudieran provocar inseguridad jurídica o reducir el estándar de derechos y libertades para los propios nacionales británicos y, viceversa, como si la legislación de la UE y las decisiones del TJUE no hubieran aportado seguridad jurídica y «corrección al alza» de los estándares nacionales a través de los cánones europeos más favorables ${ }^{71}$. Si acaso, al combinar los efectos de la ley general derogatoria y el control sobre las propias leyes, sí se paliará, lógicamente, esa inconsistencia criticada con anterioridad según la cual la cláusula «opt-out» de la CDFUE no evitaba que se incorporara al Reino Unido legislación secundaria basada en el catálogo europeo de derechos.

Las siguientes secciones no hacen sino confirmar ese espíritu nacionalista. Así, por ejemplo, la sección 3 incide en el ejercicio de las clásicas libertades comunitarias de circulación o movimientos a favor de los nacionales en el seno del Reino Unido. Desde esta óptica, y siendo consciente el Gobierno británico de que el referéndum de 23 de junio 2016 reveló una victoria ajustada a favor del Brexit gracias a Inglaterra $(53,4 \%$ a favor frente a $47,6 \%$ en contra) y a Gales $(52,5 \%$ a favor y $47,5 \%$ en contra), esta sección del Libro Blanco muestra la intención del Gobierno central de hacer guiños a las otras partes integrantes del «Estado multinacional», resaltando no solo que seguirán manteniendo y profundizando su nivel de autogobierno ${ }^{72}$, sino que ello implicará comparativamente mayores beneficios que estando dentro de la $\mathrm{UE}^{73}$; lo que, como es conocido, tiende a apaciguar el mayoritario sentimiento de integración europea existente en Escocia y, con ello, la pretensión escocesa de abandonar el Reino Unido para continuar con la unidad en la UE. En sentido parecido, la sección 4 se ve en la necesidad de realzar la compatibilidad de la ciudadanía británica y de la ciuda-

69 Así lo ha advertido DownIE, G., «Brexit: What to Make of Directives», UK Constitutional Law Association Blog, 8 septiembre 2017 (https://ukconstitutionallaw.org/2017/09/08/gordondownie-brexit-what-to-make-of-directives/, visitado el 20 de septiembre de 2017).

70 Simson CaIRD, J., «The European Union (Withdrawal) Bill: Constitutional Change and Legal Continuity», 18 de julio de 2007 (https://ukconstitutionallaw.org/2017/07/18/jack-simsoncaird-the-european-union-withdrawal-bill-constitutional-change-and-legal-continuity/, consultado el 20 de septiembre de 2017).

71 Por ejemplo, en materia de no discriminación por razón de sexo y edad de personas jubiladas en materia de acceso a medicamentos gratuitos, la STJUE Richardson de 19 de octubre de 1995 (asunto C-137/94).

72 Brexit White Paper, pp. 17-18.

${ }^{73}$ Ibidem. 
danía irlandesa para calmar la atracción de Irlanda del Norte por un estatuto semejante al de Irlanda.

Ahora bien, la mayor distancia respecto al estatuto de la ciudadanía de la UE (reconocido formalmente mediante el Tratado de Maastricht como símbolo de la creciente conciencia o sentimiento constitucional europeos) y al catálogo europeo de derechos (como elemento crucial de la dimensión constitucional material de la UE) la ponen las secciones 5, 6 y 7 del Libro Blanco del Brexit. En concreto, el mantenimiento de los derechos de los ciudadanos de la UE residentes en el Reino Unido no deja de ser una insoslayable exigencia de reciprocidad para proteger los derechos de los ciudadanos británicos residentes en la UE (sección 6), pues lo evidente es que se devalúa el estatuto de ciudadanía de la Unión a través de un control de la inmigración (sección 5) en el que los nacionales de los Estados de la UE — a los que mete en el mismo saco que a los de cualquier otra procedencia- serán bienvenidos si se hacen acreedores de la apertura británica al «talento internacional» («openness to international talent») y son especialmente competentes («especially high-skilled immigration») ${ }^{74}$.

En esa misma línea nacionalista y contraria a la inmigración, el alegato a favor de la protección de los derechos de los trabajadores británicos de la sección 7 incluso arremete contra las bases fundacionales de las Comunidades Europeas, sobre todo de una de las cuatro libertades de circulación ${ }^{75}$, a saber, la de personas, concebida esencialmente en los primeros momentos como libre circulación de trabajadores y expresión inicial de la ciudadanía (con una apuesta por su dimensión más política desde el Informe Tindemans de 1976) ${ }^{76}$. Por añadidura, y aunque el Gobierno británico se afane en el Libro Blanco del Brexit en subrayar elementos de su régimen supuestamente más favorable que el europeo en materia de protección social y laboral ${ }^{77}$, desde los sindicatos británicos se expresó el temor a que el Brexit tenga como consecuencia que no se mantenga en el Reino Unido el acervo social positivo de la legislación comunitaria, ni siquiera para los trabajadores nacionales.

74 Ibidem, p. 25.

75 Efectivamente, esa libertad de circulación se ha catalogado como el fundamento mismo de la Europa comunitaria. Véase Cartou, L., Communautés européennes, Parais, Précis Dalloz, 1991 (10. ${ }^{\mathrm{a}}$ ed.), p. 235.

76 Véase, sobre todo, el capítulo titulado «Europa de los Ciudadanos» del citado Informe elaborado por quien fuera Primer Ministro belga (a quien se confió dicho cometido en la Cumbre de París de 1974), y en donde propone medidas que hagan más visible la conciencia europea, como la unificación de pasaportes, la abolición de controles en las fronteras, o la acreditación de títulos universitarios.

77 Brexit White Paper, p. 31. 
Por lo demás, las secciones 8, 9 y 10, al promocionar nuevamente — pero en un mercado más global— la más modesta dinámica de los acuerdos bilaterales comerciales saliéndose del mercado único europeo, vuelven a reavivar la postura «anti-integracionista» económica del Reino Unido que le llevó a permanecer fuera de los Tratados constitutivos promoviendo una dinámica hostil y concurrente de libre cambio comercial a través de la EFTA, para después integrarse en las Comunidades Europeas pretendiendo beneficiarse de las ventajas del mercado común sin asumir los costes de la cohesión económica y social (recordemos, una vez más, el «I want my money back» de Thatcher).

Finalmente, tampoco parece muy coherente alejarse del catálogo europeo de derechos fundamentales abandonando el espacio de libertad, seguridad y justicia pero reconocer, como hace en la sección 11, la necesidad que el propio Reino Unido tiene (como los demás socios comunitarios) de seguir cooperando con la UE en la lucha contra el crimen y el terrorismo, algo que desgraciadamente han puesto de manifiesto los últimos atentados terroristas yihadistas realizados en suelo inglés (en lo que va de 2017: en Londres, el 22 de marzo; en Manchester, el 22 de mayo; y otra vez en Londres, el 3 de junio).

Con tales mimbres, es comprensible que el Reino Unido esté interesado en lograr la «salida tranquila y ordenada de la UE» a que se refiere la sección 12. El ajustado voto favorable al Brexit revela seguramente que, incluso haciendo balance de los costes y los beneficios, resulta cuestionable que sea mejor abandonar la UE que permanecer en ella.

\section{La desconsideración hacia el TJUE}

El Libro Blanco del Brexit ni siquiera incluye un agradecimiento por los servicios prestados al TJUE, cuando menos por el acervo que ha ido ha forjado durante décadas en materia de derechos fundamentales. Así, para el Gobierno británico lo fundamental es «tomar el control de nuestras propias leyes» (como reza la sección 2 del Libro Blanco), para «tomar el control de nuestros propios asuntos, según nos han pedido los millones de votantes a favor de dejar la UE y así poner fin a la jurisdicción del TJUE en el Reino Unido» ${ }^{78}$. Se trata de «poner fin a la competencia del TJUE en el Reino Unido», dado que está configurado como «el árbitro máximo» en las cuestiones relativas al Derecho de la UE y «como tribunal supranacional» tiene por objeto ofrecer una interpretación coherente para la aplicación de la legislación de la UE en los Estados miembros y un proceso claro para la resolución de los desacuerdos que surjan. El caso es que,

78 Brexit White Paper, p. 11. 
como «el TJUE es uno de los más poderosos tribunales supranacionales debido a los principios de primacía y efecto directo de la legislación de la UE», por ello mismo «pondremos fin a la jurisdicción del TJUE en el Reino Unido».

Y ello sobre la base de que «la soberanía del Parlamento es un principio fundamental de la Constitución del Reino Unido» que «no siempre se ha percibido así», criticando la actividad normativa de la UE en relación con el Reino Unido, esgrimiéndose que 1.056 documentos relacionados con la UE (entre los que se cuentan "propuestas de Directivas, Reglamentos, Decisiones y Recomendaciones, así como actos de delegados de la Comisión, u otros documentos como las Comunicaciones de la Comisión, Informes y Dictámenes presentados al Consejo, informes del Tribunal de Cuentas y otros»), fueron sometidos a examen parlamentario en el Reino Unido en 2016. Se concluye así que «salir de la UE significará que nuestras leyes se harán en Londres, Edimburgo, Cardiff y Belfast, y se basarán en los intereses y valores específicos del Reino Unido» ${ }^{79}$, es decir, otra contrapartida «beneficiosa» del Brexit.

En fin, según el Libro Blanco, la «Gran Ley de Derogación» asegurará «que nuestros legisladores y nuestros órganos jurisdiccionales serán quienes adopten las decisiones últimas en nuestro país» ${ }^{80}$, incidiéndose en esa sección 2 del Libro Blanco en que cualquier mecanismo de arreglo de controversias que se negocie con la UE deberá respetar «la soberanía del Reino Unido», con objeto de «proteger el papel de nuestros tribunales y maximizar la seguridad jurídica, tanto de las empresas, como de los consumidores, los trabajadores y demás ciudadanos ${ }^{81}$. Sobre este punto, en la doctrina británica se ha observado que, el temor a la erosión de la soberanía derivada de la acción de las instituciones políticas comunitarias en los años setenta del siglo veinte en el momento de la adhesión británica a las Comunidades Europeas, ha dado paso décadas más tarde en el escenario del Brexit a un resquemor por la erosión de la soberanía derivada de la actividad del Tribunal de Justicia de Luxemburgo ${ }^{82}$.

En este contexto, la campaña del Brexit ha evidenciado una paradoja más pues fue el partido conservador quien apostó por el ingreso del Reino Unido en 1973 con la oposición del partido laborista, mientras que ahora ha sido el partido tory el adalid de la salida frente a la postura mayoritariamente contraria

79 Ibidem, p. 13.

80 Idem.

81 Ibidem, p. 14.

82 Gee, G., y Young, A. L., «Regaining Sovereignty? Brexit, the UK Parliament and the Common Law», European Public Law, vol. 22, n. ${ }^{\circ}$ 1, 2016, pp. 131-148. 
del laborismo ${ }^{83}$. Desde esta última postura, efectivamente, pese a las críticas a las medidas de austeridad promovidas (en buena medida bajo el impulso de la Troika) en el ambiente de crisis económica y financiera mundial de los últimos años, y asimismo pese a la jurisprudencia clásica del TJUE que prioriza las libertades económicas relegando a un lugar accesorio los derechos sociales ${ }^{84}$, se percibe la UE como un espacio potencialmente generador de una mejora de las condiciones de vida de la ciudadanía. Y el TJUE, como garante último del funcionamiento de la UE como Comunidad de Derecho, sin perjuicio de esa tensión dialéctica entre lo económico y lo social, ha jugado igualmente un papel nada despreciable como defensor pretoriano de los derechos, incluidos los de carácter social ${ }^{85}$.

Sin embargo, parece obvio que al Reino Unido, según la hoja de ruta del Brexit, no solo no le ha gustado la jurisprudencia pretoriana sobre derechos fundamentales, sino que incluso ha acudido al propio TJUE para pretender obtener una fiscalidad más favorable ${ }^{86}$ o para defender en lo referente al espacio de libertad, seguridad y justicia todavía más su posición excepcional (ya manifestada en su exclusión del espacio de Schengen) ${ }^{87}$. En otras palabras, el Gobierno británi-

83 Como sintetiza Fabre, C., «se observan en el curso de la historia de la segunda mitad del siglo xx temáticas y relaciones de fuerza relativamente constantes. Los temas de la política agrícola común, de la contribución al presupuesto y de la integración política acaban siendo regularmente puntos de fricción entre el Reino Unido y la UE. Sin embargo, el posicionamiento de los actores ha cambiado, pues los laboristas eran más bien antieuropeístas al principio y los conservadores estaban más bien a favor de la integración, postura que se ha invertido actualmente. Este breve repaso histórico nos permite comprender el contexto en el que se desenvuelve el debate actual», «Royaume-Uni et UE: plus de 40 ans de relations dévoilées «, Le Taurillon, 25 de enero de 2013, ya cit.

84 Por tal razón, tras el Brexit, ya sin la presión británica en el seno de la UE, se ha puesto el acento en la necesidad de priorizar otra vez la Europa Social, BoscH, G., «After Brexit: Prioritising a Social Europe», Social Europe, 24 de enero de 2017, https://www.socialeurope.eu/2017/01/brexitprioritising-social-europe/ (acceso el 5 de junio de 2017)

85 Véase, entre otros, el trabajo de De Schutter, O. y Dermine, P., «The role of the Court of Justice of the European Union", en The Two Constitutions of Europe: Integrating Social Rights in the New Economic Architecture of the Union, Université Catholique de Louvain, CRIDHO Working Paper 2016/2, diciembre de 2016, especialmente pp. 18-23, http://cridho.uclouvain.be/documents/Working. Papers/CRIDHO-WP-2016-2-ODS-PD-22.12.2016-C.pdf (acceso el 20 de junio de 2017).

86 Por ejemplo, STJUE Comisión Europea c. Reino Unido de 4 de junio de 2015 (asunto C-161/14), sobre condena al Reino Unido por utilizar un tipo reducido de IVA en su territorio contrariando la legislación comunitaria.

87 Puede verse la STJUE Reino Unido (apoyado por Irlanda y por República Eslovaca) c. Consejo de la Unión Europea (apoyado por España, Países Bajos y Comisión Europea) de 18 de diciembre de 2007 (asunto c-137/05), mediante la que se desestima el recurso de anulación formulado por 
co ha llevado casos ante el TJUE para impulsar judicialmente pretensiones políticas de excepcionalidad, no precisamente guiadas por la solidaridad y la consecución de estándares comunes, a pesar de que la jurisprudencia comunitaria haya tenido mucho que ver con la mejora de los estándares internos del propio sistema constitucional británico (como pone de manifiesto el famoso asunto «Factortame» y su impacto en el principio de soberanía del Parlamento británico al consagrarse la primacía del Derecho europeo ${ }^{88}$.

\section{La hoja de ruta en la encrucijada: la tenue frontera entre la Unión Europea y el Consejo de Europa}

El Brexit constituye un desafío al Derecho constitucional europeo, y particularmente, a la Europa de los derechos, de alcance impredecible. Y ello porque la Europa comunitaria de los derechos y libertades se inscribe en el más amplio

Reino Unido contra el Reglamento (CE) n. ${ }^{\circ} 2252 / 2004$ del Consejo, de 13 de diciembre de 2004, sobre normas para las medidas de seguridad y datos biométricos en los pasaportes y documentos de viaje expedidos por los Estados miembros.

${ }^{88}$ Bombillar SÁEnZ, F. M. resume meridianamente ese impacto: «Este sacrosanto principio básico del constitucionalismo británico entró en crisis en 1973, con la incorporación del Reino Unido a la CEE, y, definitivamente, en los años noventa, con la serie de sentencias recaídas sobre el asunto «Factortame» (Caso C-213/89), en relación con la «Merchant Shipping Act», de 1988. Fue entonces cuando se declaró, tras un largo "diálogo" entre el TJCE y los Tribunales ingleses, la posibilidad de "inaplicar" una ley estatal, aprobada por el Parlamento de Westminster, si ésta fuese contraria al Derecho Comunitario (algo hasta entonces enteramente inconstitucional). Los propios Jueces ingleses legitimaron este modo de actuación, entendiendo que, voluntariamente, el Parlamento de Westminster había autolimitado su soberanía en este sentido al aprobar, en 1972, la «European Communities Act». Lord Bridge, como analiza de modo crítico Murphy, apoyó su posición a este respecto en tres argumentos: el Reino Unido formuló su solicitud para formar parte de la Unión Europea cuando el principio de primacía estaba en esta organización ya asentado («contractarian argument»); es necesario para el buen funcionamiento de la Unión que este principio sea respetado («functional argument»); y, por último, precisamente así lo refrendó por escrito el propio Parlamento británico cuando, en 1972, redactó la «section» 2 (4) («textual argument»). Esta posición consagró, en suma, la primacía del Derecho europeo sobre el inglés, de modo que los Tribunales del Reino Unido pueden desde entonces inaplicar las normas que aprueba el Parlamento de Westminster cuando éstas entren en contradicción con los postulados del Derecho Europeo. Es más, este posicionamiento implica también reconocer que el propio Parlamento británico, en 1972, alteró otro de los principios constitucionales fundamentales de este Estado: el que impide la aprobación de Leyes que no se puedan modificar en el futuro, limitando su poder. Para Murphy, en el marco de una Constitución no escrita, otorgar a los Tribunales este poder, por el que se puede invalidar una norma dictada por el Parlamento, puede desembocar en una crisis constitucional», «El sistema constitucional del Reino Unido», Revista de Derecho Constitucional Europeo, n. ${ }^{\circ}$ 15, 2011, pp. 155-157. 
sistema europeo de derechos humanos y, por tanto, la frontera entre la UE (de la que el Reino Unido sale) y el Consejo de Europa (en el que por el momento permanece) es tenue, tanto más cuanto que desde los propios Tratados constitutivos esa colaboración se erigió en un imperativo del normal funcionamiento del edificio comunitario.

Esa estrecha colaboración se ha ido consolidando y fortaleciendo naturalmente mediante las reformas más importantes de los Tratados comunitarios, que se han ido refiriendo a los dos instrumentos más emblemáticos del Consejo de Europa (el Convenio Europeo de Derechos Humanos y la Carta Social Europea) hasta llegar a introducirse en el Tratado de Lisboa el mandato de adhesión al citado Convenio ${ }^{89}$; sin perjuicio de otros textos relevantes del Consejo de Europa que la UE ha ido asumiendo como Parte Contratante (como por ejemplo, la Convención de Oviedo de 1997 sobre biomedicina y derechos humanos).

En estas coordenadas, algunas de las líneas rojas marcadas por el Libro Blanco del Brexit van a colisionar con la jurisprudencia del TEDH, con la que el TJUE había venido convergiendo en asuntos relevantes en una acción de sinergia favorecida en general por la «doctrina Bosphorus» ${ }^{90}$. Por ejemplo, en relación con el control de la inmigración y el estatuto de los residentes británicos o demás ciudadanos europeos (secciones 5 y 6), materia sobre la que el TEDH ya ha incidido en los conocidos como «asuntos Dublín» ${ }^{91}$. De modo que la hoja de ruta del Brexit pondrá fin a la jurisdicción del TJUE, pero el Reino Unido seguirá estando sometido paradójicamente a la del TEDH, más favorable en materia migratoria ${ }^{92}$.

89 Como es sabido, la adhesión de la UE al CEDH vino impuesta por el Tratado de Lisboa (a través el artículo 6.2 TUE, que a su vez había venido precedido por la nueva redacción del artículo 59.2 CEDH dada por el Protocolo n. $\left.{ }^{\circ} 14\right)$, pero ha quedado por el momento paralizada tras el Dictamen 2/13 del Pleno del TJUE, de 18 de diciembre de 2014. Desde luego, con el Brexit ya sobran las disquisiciones acerca de la evidentemente poco entusiasta posición del Reino Unido con relación a la adhesión de la UE al CEDH, como ha observado GRAGL, P. en «Of Tangled and Truthful Hierarchies: EU Accession to the ECHR and is Possible Impact on the UK's Relationship with European Human Rights», en el colectivo The UK and European Human Rights: A Strained Relationship?, op.cit., p. 275.

${ }^{90}$ Que postula, en principio, la presunción de conformidad del Derecho de la UE en relación con CEDH: así se estableció mediante la STEDH (Gran Sala) Bosphorus Hava Yollari Turzim ve Ticaret Anonim Sirketi c. Irlanda de 30 de junio de 2005.

${ }^{91}$ Ficha Temática — Asuntos «Dublín», http://www.echr.coe.int/Documents/FS_Dublin_ SPA.pdf (acceso el 5 de junio de 2017).

92 Sobre este particular, García Mahamut, R.: «Por lo que afecta al TEDH recordemos la trascendencia de su jurisprudencia en el ámbito de las cláusulas discrecionales — de las Directivas y Reglamento de Dublín_ que son aplicadas por los Estados miembros y, en el caso concreto, ha delimitado la actuación de los Estados a través de una interpretación y aplicación acorde con el 
En este mismo sentido, es verdad que la línea roja tendente a teóricamente blindar los derechos de los trabajadores británicos (sección 7 del Libro Blanco del Brexit) y que, consecuentemente, perjudicaría a los trabajadores no británicos en el acceso a prestaciones sociales o a la protección por desempleo, ha quedado avalada en ciertas circunstancias por el Tribunal de Justicia de Luxemburgo $^{93}$. Ahora bien, la jurisprudencia social del TEDH en ese ámbito resulta, en general, menos favorable a las pretensiones nacionalistas británicas ${ }^{94}$.

Además, las mencionadas líneas rojas todavía se enfrentan a mayores obstáculos si se repara en el alcance del tratado europeo de derechos sociales por excelencia, la Carta Social Europea, como ya se dijo, ratificada por el Reino Unido en su versión de 1961. A este respecto, el Reino Unido aceptó tanto el artículo 18 referente al ejercicio libre de una actividad lucrativa en el territorio de cualquier Parte Contratante, como el artículo 19 relativo al estatuto de los trabajadores migrantes y miembros de sus familias. A título de ejemplo, el Comité Europeo de Derechos Sociales determinó que los nacionales de otros Estados Partes en la Carta Social pueden pedir prestaciones de asistencia social en las mismas condiciones que los ciudadanos británicos, lo que de hecho con-

principio de no devolución interpretado a la luz de la prohibición de la tortura y los tratos inhumanos o degradantes. De especial interés, por ejemplo, resulta la STEDH en el caso MSS v Belgium and Greece, de 21 de enero de 2011, condenando a Bélgica y Grecia por violación de los artículos 3 y 13 del Convenio. Esta sentencia condicionó la nueva redacción dada al artículo 17.1 del Reglamento de Dublín III sobre las cláusulas discrecionales relativas al Estado miembro que puede decidir examinar una solicitud de protección internacional aun cuando el examen no le incumba en virtud de los criterios establecidos en el Reglamento. No podemos menos que compartir la apreciación de que las sentencias del TEDH se han convertido en garantías de la protección internacional en la aplicación por parte de los Estados miembros de las Directivas y Reglamentos que inciden directamente en la protección internacional de los demandantes de asilo o de cualquier otra protección subsidiaria», en «La ductilidad del derecho a la protección internacional (refugio y protección subsidiaria) ante las crisis humanitarias: un desafío para Europa y para el sistema europeo común de asilo», Teoría y Realidad Constitucional, n. ${ }^{\circ} 38$, 2016, pp. 218-219.

93 Véase, por ejemplo, STJUE Reino Unido (apoyado por Irlanda) c. Consejo de la UE (apoyado por la Comisión Europea) de 18 de diciembre de 2014 (asunto C-81/13), mediante la que se desestima el recurso de anulación formulado por el Reino Unido contra la Decisión 2012/776/UE del Consejo, de 6 de diciembre de 2012, relativa a la posición que deberá adoptar la Unión Europea en el seno del Consejo de Asociación establecido por el Acuerdo por el que se crea una asociación entre la Comunidad Económica Europea y Turquía con respecto a la adopción de las disposiciones de coordinación de los sistemas de seguridad social.

${ }^{4}$ De nuevo, De Schutter, O., y Dermine, P., The Two Constitutions of Europe: Integrating Social Rights in the New Economic Architecture of the Union, op. cit. 
dujo al Reino Unido a reformar la normativa relativa a la seguridad social en materia migratoria y de asilo en $2000^{95}$.

Como es obvio, la Gran Ley de Derogación prevista en la hoja de ruta del Brexit no puede ni debe ir contra ese acervo social del Consejo de Europa. Pero el compromiso de la sección 6 del Libro Blanco del Brexit — recordemos, asegurar los derechos de los ciudadanos de la UE que se encuentren en el Reino Unido y los de los ciudadanos británicos que estén en cualquier país de la UE- no puede dejar de provocar incertidumbre e inquietud, por ejemplo, en los cientos de miles de ciudadanos jubilados europeos que viven fuera de su país: tanto en los nacionales de cualquier país de la UE residentes en el Reino Unido, puesto que este Estado no ha aceptado el conjunto de compromisos sobre seguridad social establecidos en el artículo 12 de la Carta Social Europea en virtud del sistema de ratificación «a la carta», como en los británicos que residan en cualquier país de la UE pues también allí habrá que aceptar esa misma disposición ${ }^{96}$.

Y lo que es peor, como ya se ha apuntado, las prioridades trazadas en el Libro Blanco del Brexit no permiten descartar que, al igual que ha estado presente en el debate sobre el Brexit la denuncia del CEDH (y el consiguiente fin de la jurisdicción del TEDH), como propuesta tanto alternativa como complementaria, las voces antieuropeístas apunten la posibilidad de denunciar de la Carta Social Europea y rechazar la competencia del Comité Europeo de Derechos Sociales ${ }^{97}$.

95 Véase la referencia a esa jurisprudencia del Comité Europeo de Derechos Sociales en la ficha referente al impacto de la Carta Social Europea en el Reino Unido, https://rm.coe.int/1680644aa9 (acceso el 5 de junio de 2017), p. 6.

96 En relación con ello, en lo que afecta a España, ha indicado GALLEGo LOSADA, R. que hay una serie de «problemas intrínsecos a la propia gestión de la solución que se articule: desde afinar los desajustes que afectan a la balanza de pagos entre países por los complejos mecanismos de compensación como armonizar una política coordinada y uniforme por parte de las diferentes CCAA en cuanto a la futura cartera de prestaciones sanitarias que deben servirse a los británicos en el futuro», «Después del Brexit. Un nuevo desafío para la sanidad española», en el colectivo Los retos actuales de la asistencia sanitaria española en el contexto de la Unión Europea, Actas del XIII Congreso Nacional de la Asociación Española de Salud y Seguridad Social, Murcia, Ediciones Laborum, 2016, pp. 220.

97 Esas voces apelan, como en otros ámbitos, a la posición de Suiza, que no es Parte Contratante de la Carta del Consejo de Europa, y subrayan desde una posición claramente proteccionista y antieuropeísta los aspectos positivos del particularismo social helvético a través de la crítica al modelo social europeo representado por dicho tratado. Entre otros, BrEssard, P.: «El Parlamento suizo siempre ha rechazado ratificar la Carta Social Europeo, por ejemplo, al ser considerada como un programa implícito de destrucción de empleos. Los empresarios suizos tienen completa libertad de despedir y, por tanto, de contratar, y los resultados hablan por sí mismos: una tasa de paro comparativamente baja (especialmente en los jóvenes), una tasa de participación récord en el mercado de trabajo y un alto grado de satisfacción de los empleados. La flexibilidad del mercado 
En fin, el Brexit tendrá efectos en muchos ámbitos y tanto para el Reino Unido, como para la UE y Europa en sentido más amplio ${ }^{98}$.

\section{REFLEXIONES FINALES: LA APUESTA \\ POR EL FORTALECIMIENTO DE LA EUROPA DE LOS DERECHOS, PESE AL BREXIT}

Llegados a este punto, el mejor modo de mitigar el impacto del Brexit en la Europa de los derechos radica, en nuestra opinión, en poner el énfasis, no tanto en las debilidades de la UE frente al desafío británico, sino en la fragilidad de las inconsistencias y contradicciones del vacilante europeísmo del Reino Unido. Un ambiguo y vacilante europeísmo, cabe recordar, presente en toda la construcción europea tanto en el pensamiento y obra de insignes personajes británicos como Churchill como en la postura oscilante del tradicional bipartidismo desde la adhesión a las Comunidades Europeas en enero de 1973 hasta el reciente referéndum del Brexit en junio de 2016.

Cuando el constitucionalismo británico parecía haber ido insertándose en el más amplio y emergente Derecho constitucional europeo, el Brexit no ha hecho sino aflorar las sucesivas excepciones británicas a la Europa comunitaria de los derechos y los recelos hacia los instrumentos más emblemáticos del Consejo de Europa. A este respecto, el Libro Blanco del Brexit refleja una sobredosis de nacionalismo que, a su vez, denota una intolerante e insolidaria alergia hacia el estatuto de la ciudadanía europea y el catálogo recogido en la Carta de los Derechos Fundamentales de la UE.

En puridad, esa hoja de ruta del Brexit comporta un abandono del orden constitucional europeo de los derechos que, a decir verdad, coloca al Reino Unido (una inconsistencia más en su vacilante andadura europea) en una encrucijada, precisamente por la tenue frontera que existe entre el divorcio con la UE y el mantenimiento de su vínculo con el Consejo de Europa.

En sentido opuesto, la retirada del Reino Unido debe irremediablemente concebirse como una nueva oportunidad para seguir fortaleciendo la construcción

de trabajo suizo se asocia a un sistema de formación menos ciegamente academizado, que permite una integración real de los jóvenes desde los quince años», «Brexit: le Royaume-Uni bientôt comme la Suisse avec l'UE», Revista electrónica Contrepoints, https://www.contrepoints. org/2016/06/28/258465-suisse-inspirer-royaume-uni (visitada el 20 de julio de 2017, traducción de la autora).

98 Sobre ello reflexiona Freixes SanjuÁn, T., en El Brexit y sus implicaciones, https://teresafreixes.wordpress.com/2016/06/24/el-brexit-y-sus-implicaciones/ (consultado el 12 de julio de 2017). 
europea y el orden constitucional de los derechos puesto que, si bien en líneas generales resultaba preferible contar con el socio británico dentro que fuera de la UE, debe reconocerse que cada excepción y cesión en su beneficio de dicho socio no iba precisamente en la línea de construir la casa común. Piénsese que de no haber prosperado el Brexit el acuerdo alcanzado a principios de 2016 por la UE con Cameron ${ }^{99}$, que dejaba muy malherido el proceso de integración europea, hubiera debido entrar en vigor.

En suma, el Brexit debe interpelarnos necesariamente para efectuar una lectura en clave positiva y subir la apuesta por el fortalecimiento de la Europa de los derechos y, por ende, de la dimensión sustancial del constitucionalismo europeo. La experiencia del Brexit no debe provocar una crisis de fe en los valores europeos, sino un fortalecimiento del espíritu europeísta (profundización en el proyecto integrador, «más Europa ${ }^{100}$ de tal suerte que, más allá de incentivar a otros socios euroescépticos a embarcar a su ciudadanía en una operación similar de retirada de la UE, tiene que animar a todos los demás socios comunitarios a resaltar lo que ésta ha supuesto no solo para consolidar la paz y el imperio de la ley en el continente europeo, sino igualmente para apuntalar la transición democrática y consolidar el Estado social y democrático de Derecho en cada país. El ejemplo paradigmático de España nos exime de ulteriores reflexiones.

Title:

The Brexit and its impact on the Europe of human rights: the british challenge to European Constitutional Law.

Summary:

I. Introduction: the Brexit as a result of the eurosceptic british constitutionalism. II. The United Kingdom as a promoter (paradoxically) of a comprehensive Europe of rights. 1. The emblematic constitution in London of the Council of Europe. 2. The late assumption of the basic standards of European rights culture. III. The initial

99 Véase el ya mencionado anexo I de las Conclusiones del Consejo Europeo celebrado los días 18-19 de febrero de 2016.

100 Heinig, H. M., «Is Europe in a Crisis of Faith?», German Journal Law, vol 17 (Brexit Suplement), 2016, p. 30. 
exclusion and successive british exceptions to the european rights community. 1. The EFTA and the promotion of the integrated Europe of rights, without integrating it. 2. Partial exceptions on rights in the revisions of the European Treaties. 3. The total amendment to the Europe of rights: rejection of the Charter of Fundamental Rights of the European Union. IV. The Brexit road map as an abandonment of the European constitutional order of rights. 1. Distancing from the European catalog of rights. 2. Disregard for the CJEU. 3. The road map at the crossroads: the thin frontier between the European Union and the Council of Europe. V. Final thoughts: the commitment to the strengthening of a Europe of rights, despite Brexit.

\title{
Resumen:
}

El presente artículo examina críticamente la decisión histórica de retirada de la UE adoptada en el Reino Unido en el referéndum del Brexit de 23 de junio de 2016, desde una perspectiva de Derecho Constitucional Europeo. En efecto, se hace hincapié en el impacto negativo del Brexit en la construcción de una Europa de los derechos humanos. Desde este punto de vista, se destaca la permanente actitud vacilante del Reino Unido entre el reclamo de la supremacía británica y la necesidad de fortalecer una cultura constitucional europea común, teniendo en cuenta las dinámicas de la «adhesión» y de la «exclusión parcial» tanto en relación con la UE como con el Consejo de Europa y sus principales instrumentos de derechos humanos. Por otra parte, el artículo somete a análisis las inconsistencias del «Libro Blanco del Brexit» presentado como documento oficial del Gobierno británico en el campo de los derechos fundamentales. En fin, se concluye que el Brexit puede ser una decisión histórica equivocada que debilita la cultura constitucional británica y, correlativamente, una oportunidad para que los demás Estados miembros de la UE optimicen el proceso de integración europea y la calidad de sus propios regímenes democráticos.

\begin{abstract}
:
This essay critically examines the historical decision of withdrawal from the EU adopted in United Kingdom in the Brexit referendum of 23 June 2016 under a European Constitutional Law perspective. Indeed, the focus is put on the negative impact of the Brexit in building a Europe of human rights. From this point of view, the author highlights the United Kingdom's permanent hesitation between a claim for the British supremacy and a need for strengthening a Common European Constitutional culture, by taking into account the
\end{abstract}


dynamics of either «accession» or «partial out-puts» in relation to both the EU and the Council of Europe and their main human rights instruments. On the other hand, the paper submits to scrutiny the inconsistencies of the British Government's official «Brexit White Paper» in the field of fundamental rights. The author concludes that the Brexit might be a wrong historic decision weakening the British Constitutional culture and, correlatively, an opportunity for the other EU Member States to optimize the European integration process as well as the quality of their own democratic regimes.

\section{Palabras clave:}

Constitucionalismo multinivel - cultura europea - derechos fundamentales - opciones democráticas - valores solidarios.

Key words:

Multi-level Constitutionalism - European Culture - Fundamental Rights - Democratic Choices - Solidarity Values. 
